\title{
Optimization of Acoustic Pressure Measurements for Impedance Eduction
}

\author{
M. G. Jones, ${ }^{*}$ W. R. Watson ${ }^{\dagger}$ and D. M. Nark ${ }^{\ddagger}$ \\ NASA Langley Research Center, Hampton, VA 23681-2199, USA \\ 13th AIAA/CEAS Aeroacoustics Conference \\ 21-23 May 2007; Rome, Italy
}

\begin{abstract}
A $S$ noise constraints become increasingly stringent, there is continued emphasis on the development of improved acoustic liner concepts to reduce the amount of fan noise radiated to communities surrounding airports. As a result, multiple analytical prediction tools and experimental rigs have been developed by industry and academia to support liner evaluation. NASA Langley has also placed considerable effort in this area over the last three decades. More recently, a finite element code (Q3D) based on a quasi-3D implementation of the convected Helmholtz equation has been combined with measured data acquired in the Langley Grazing Incidence Tube (GIT) to educe liner impedance in the presence of grazing flow. A new Curved Duct Test Rig (CDTR) has also been developed to allow evaluation of liners in the presence of grazing flow and controlled, higher-order modes, with straight and curved waveguides. Upgraded versions of each of these two test rigs are expected to begin operation by early 2008. The Grazing Flow Impedance Tube (GFIT) will replace the GIT, and additional capabilities will be incorporated into the CDTR. The current investigation uses the Q3D finite element code to evaluate some of the key capabilities of these two test rigs. First, the Q3D code is used to evaluate the microphone distribution designed for the GFIT. Liners ranging in length from 51 to $610 \mathrm{~mm}$ are investigated to determine whether acceptable impedance eduction can be achieved with microphones placed on the wall opposite the liner. This analysis indicates the best results are achieved for liner lengths of at least $203 \mathbf{~ m m}$. Next, the effects of moving this GFIT microphone array to the wall adjacent to the liner are evaluated, and acceptable results are achieved if the microphones are placed off the centerline. Finally, the code is used to investigate potential microphone placements in the CDTR rigid wall adjacent to the wall containing an acoustic liner, to determine if sufficient fidelity can be achieved with 32 microphones available for this purpose. Initial results indicate 32 microphones can provide acceptable measurements to support impedance eduction with this test rig.
\end{abstract}

\section{Nomenclature}

$\begin{array}{ll}c & \text { ambient sound speed, } \mathrm{m} / \mathrm{s} \\ f & \text { frequency, } \mathrm{Hz} \\ i & \sqrt{-1} \\ k & \text { free space wavenumber, } \mathrm{m}^{-1} \\ L, H, W & \text { test section length, height and width, respectively, } \mathrm{m} \\ L_{1}, L_{2} & \text { axial locations of leading and trailing edges of liner, respectively, } \mathrm{m} \\ m & \text { mode order for mode set up between opposing rigid walls } \\ M_{0} & \text { uniform flow Mach number } \\ p & \text { complex acoustic pressure, Pa } \\ p_{s}, p_{m} & \text { acoustic pressures, at source plane and measurement locations, respectively, Pa } \\ x, y, z & \text { axial, vertical and spanwise locations, respectively, } \mathrm{m}\end{array}$

*Senior Research Scientist, Research \& Technology Directorate, Structural Acoustics Branch, Mail Stop 463; Michael.G.Jones@NASA.GOV. Senior member of AIAA.

${ }^{\dagger}$ Senior Research Scientist, Research \& Technology Directorate, Computational Modeling and Simulation Branch, Mail Stop 128; Willie.R.Watson@NASA.GOV. Senior member of AIAA.

${ }^{\ddagger}$ Research Scientist, Research \& Technology Directorate, Structural Acoustics Branch, Mail Stop 463; Douglas.M.Nark@ NASA.GOV. Member of AIAA. 
Symbols:

$\begin{array}{ll}\rho & \text { ambient density, } \mathrm{kg} / \mathrm{m}^{3} \\ \theta & \text { normalized acoustic resistance } \\ \omega & \text { circular frequency, rad } / \mathrm{s} \\ \chi & \text { normalized acoustic reactance } \\ \zeta & \theta+i \chi, \text { normal incidence normalized (with respect to } \rho c \text { ) acoustic impedance }\end{array}$

Abbreviations:

$\begin{array}{ll}\text { CDTR } & \text { Curved Duct Test Rig } \\ \text { GFIT } & \text { Grazing Flow Impedance Tube } \\ \text { GIT } & \text { Grazing Incidence Tube } \\ \text { Q3D } & \text { Quasi-3D Finite Element Method }\end{array}$

Subscripts:

e quantity educed from measured data

err error in educed quantity relative to true value

exit quantity measured in computational exit plane

mean mean error in educed quantity, based on 11 trials

set quantity set as input for use in Q3D code (in source mode)

unc approximate $95 \%$ confidence estimate of random uncertainty for error

in educed quantity $\left(\theta_{\text {err }}\right.$ or $\left.\chi_{\text {err }}\right)$

Note: An $e^{i \omega t}$ time convention is used throughout this paper.

\section{Introduction}

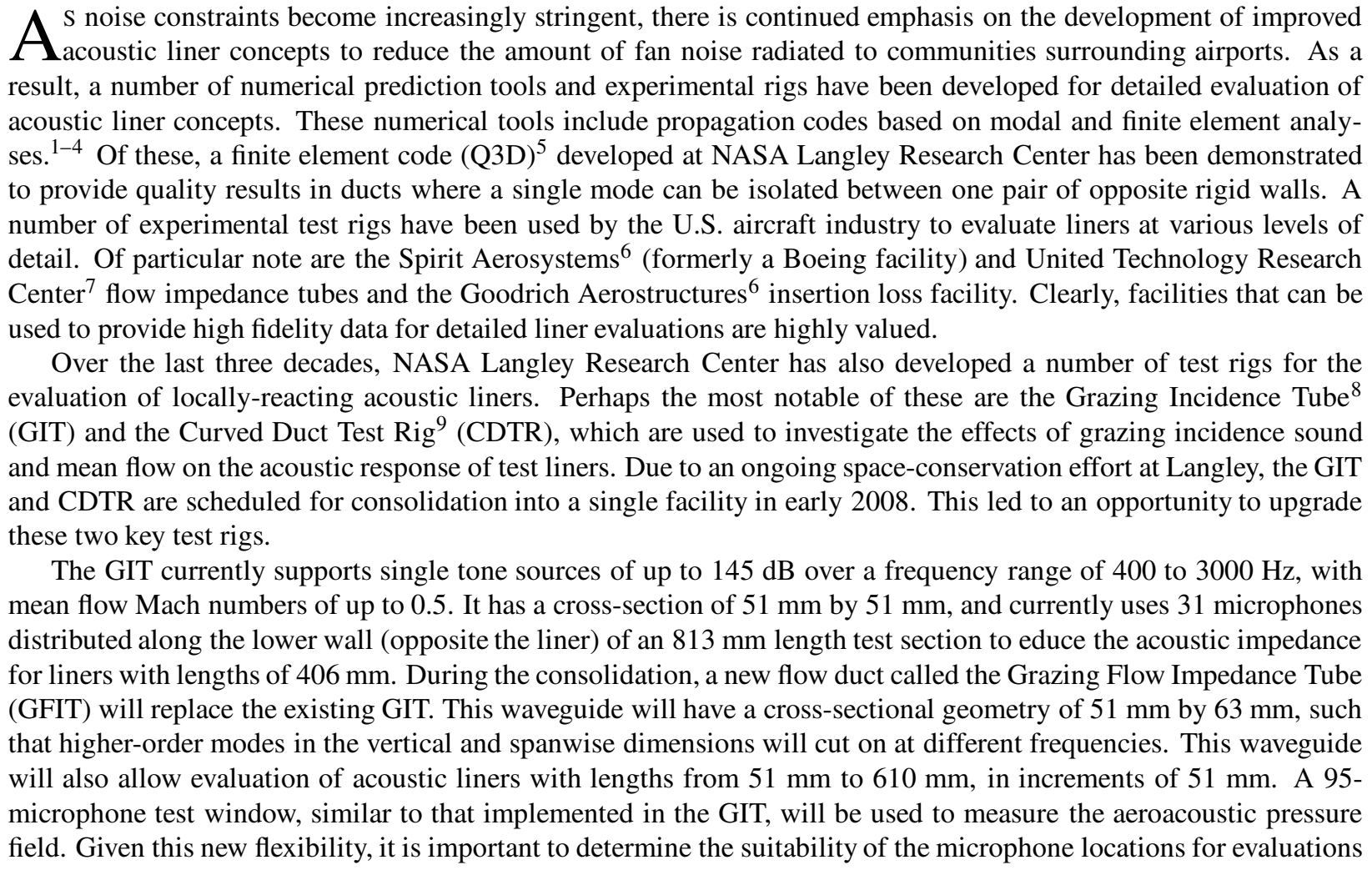


of liners of lengths as short as $51 \mathrm{~mm}$. The first goal of the current investigation is to use the finite element propagation code (Q3D) to provide an assessment of the capability to properly educe impedance with liners of different lengths.

The 152-mm by 381-mm CDTR allows investigation of liners in the presence of aeroacoustic environments more representative of aircraft engine nacelles. The CDTR can be configured as a curved (in the axial direction) duct, with offsets from zero (straight duct) to one duct width $(152 \mathrm{~mm}$ ), and can accept $813 \mathrm{~mm}$ length (in straight duct configuration, longer in curved duct configuration) liners on two opposing walls. Arrays of microphones are flush-mounted in the rigid wall sections well upstream and downstream of the liner to measure the modal amplitudes and phases of forward and backward propagating modes in each hardwall section. By use of a feedback control system between the acoustic drivers and the upstream microphone array, selected modes can currently be isolated at frequencies up to approximately $2400 \mathrm{~Hz}$, in the presence of up to Mach 0.275 grazing flow. When moved to the new Liner Technology Facility, this mean flow capacity will be increased to support up to Mach 0.5 grazing flow. By measuring the modal amplitudes and phases (for forward and backward propagating modes) in the upstream and downstream hardwall sections, the CDTR can currently be used as a transmission loss waveguide to compare attenuations achieved with various noise reduction concepts. However, since the attenuation does not provide a unique value for the test liner impedance, it is desired to modify this duct to support impedance eduction of test liners (for locally-reacting liners, the liner impedance is an intrinsic property that is independent of duct geometry).

The impedance eduction method developed by NASA Langley has been designed for ducts with one wall treated and the opposite wall populated with microphones. This method will need modification to work with the CDTR, since the wall opposite the liner is not a hard wall. Instead, a new array of microphones will be placed on a wall adjacent to the treated wall, over the entire length of the test duct $(2032 \mathrm{~mm})$. In a parallel effort, a hybrid (combination of modal and finite element methods) approach is being investigated for impedance eduction in the CDTR. The results of the study described herein will be used in conjunction with that approach to determine the optimum distribution of microphones to achieve maximum impedance eduction fidelity. Thus, the current investigation seeks to develop a tool for evaluating potential CDTR microphone distributions to support acoustic liner impedance eduction.

The first portion of the investigation is conducted in two stages. First, the Q3D code is used to compute the acoustic pressure profile that will be present at the microphone locations on the wall opposite the liner in the GFIT, for a selected liner length and impedance. As a consistency check, the Q3D code is then used to educe the 'unknown' liner impedance from these synthesized data, to ensure that the original liner impedance is correctly recovered. Finally, random scatter is added to the synthesized data, and the Q3D code is again used to educe the liner impedance. Comparison of these results provides an indication of the effects of liner length and measurement uncertainty on the expected results. This process is conducted for a number of conditions (two mean flow velocities, two frequencies, two liner impedances and five liner lengths) to evaluate, at least partially, the effects of each parameter on the impedance eduction process. This entire process is then repeated for two other configurations, in which the microphones are assumed to be on the wall adjacent to the liner, to confirm the suitability of placing microphones on the adjacent wall (as will be required in the CDTR).

Finally, the code is used to investigate potential microphone placements in the CDTR rigid wall adjacent to the wall containing the acoustic liner, to determine if sufficient fidelity can be achieved with a maximum of 32 microphones (currently a hardware constraint). For convenience, the source is constrained to be a plane wave in the current analysis. For this portion of the study, the Q3D code is again used to compute the acoustic pressure profile that will be present at any possible microphone location in the duct for a given liner impedance. A number of randomly selected microphone arrangements are then evaluated to determine if the liner impedance can be properly educed with sufficient fidelity.

In summary, the two key goals of the current investigation are to (1) determine the efficacy of using the Q3D code and the Grazing Flow Impedance Tube microphone array to educe the impedance of variable length liners, and (2) develop a tool for evaluation of potential microphone distributions in the Curved Duct Test Rig to support impedance eduction. A description of the analysis is provided in Section II. Section III describes an investigation to evaluate the effects of liner length, microphone placement, and measurement uncertainty on an impedance eduction process based on the Q3D code. In Section IV, these combined results are used to develop a procedure for developing an optimum microphone distribution to support impedance eduction with the CDTR. Concluding remarks regarding some of the more significant results are provided in Section V.

\section{Analysis}

$T^{H E}$ analysis used in the current investigation has been presented in a previous paper, ${ }^{5}$ but is summarized here for convenience. A schematic of the three-dimensional flow duct and Cartesian coordinate system is provided in 


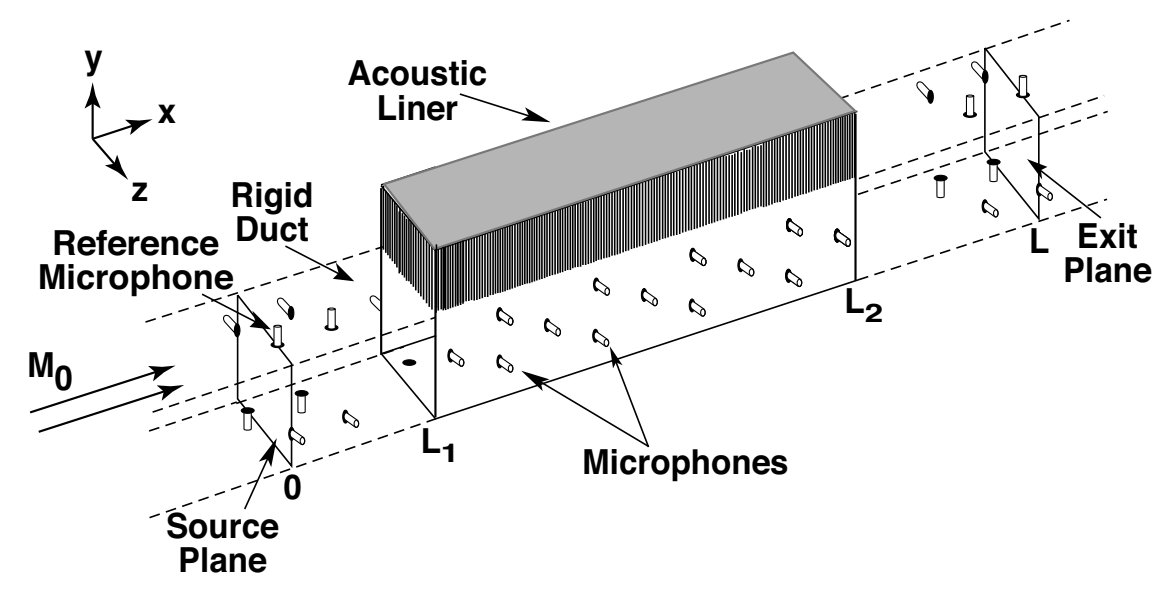

Figure 1. Sketch of flow duct test window.

figure 1. The lower wall and the two side walls of the duct are rigid, and the source and exit planes are located at $x=0$ and $x=L$, respectively. The test liner constitutes the portion of the upper wall between $L_{1} \leq x \leq L_{2}$, and the upper wall is rigid outside this region. The locally-reacting liner is assumed to present a uniform normalized impedance, $\zeta$, to the aeroacoustic field in the duct. The mean flow through the duct is assumed to be uniform, with flow from left to right at subsonic Mach number, $M_{0}$. Pertinent dimensions for the three Langley flow ducts are:

\begin{tabular}{|c|c|c|c|c|c|}
\hline Waveguide & $L, \mathrm{~mm}$ & $H, \mathrm{~mm}$ & $W, \mathrm{~mm}$ & $L_{1}, \mathrm{~mm}$ & $L_{2}, \mathrm{~mm}$ \\
\hline Grazing Incidence Tube (GIT) & 813 & 51 & 51 & 203 & 610 \\
Grazing Flow Impedance Tube (GFIT) & 1016 & 63 & 51 & $203^{1}$ & $813^{1}$ \\
Curved Duct Test Rig (CDTR) & 2032 & 381 & 152 & 610 & $1422^{3}$ \\
\hline
\end{tabular}

${ }^{1}$ Dimensions provided are for maximum liner length; liner lengths of 51 to $610 \mathrm{~mm}$ are supported

${ }^{2}$ Liner are placed on the side wall

${ }^{3}$ For straight duct configuration

\section{A. Differential Equation and Boundary Conditions}

A plane-wave source is assumed for the current investigation. Therefore, a quasi-3D finite element propagation A code (Q3D) previously developed by NASA Langley Research Center can be used for the analysis. Inputs for this code are the source plane acoustic pressure, mean flow Mach number, spanwise $(z)$ mode number, and the exit plane impedance. The Q3D code can be configured in propagation mode to provide predictions of the acoustic pressure distribution throughout the duct. It can also be configured in impedance eduction mode to allow the impedance of the test liner to be educed from a measured acoustic pressure distribution. This model greatly reduces the computational time and memory required to obtain the numerical solution by reducing the 3-D problem to a 2-D problem for each spanwise mode order. When the side-walls of the duct are rigid, as in the duct depicted in figure 1, the acoustic pressure field and sound source in the presence of a uniform mean flow may be expanded into the following Fourier series of hard wall duct modes

$$
\begin{gathered}
p(x, y, z)=\sum_{m=0}^{\infty} p_{m}(x, y) \cos \left(\frac{m \pi z}{W}\right) \\
p_{s}(y, z)=\sum_{m=0}^{\infty} G_{m}(y) \cos \left(\frac{m \pi z}{W}\right)
\end{gathered}
$$

where the function $p_{m}$ satisfies the convected Helmholtz equation

$$
\left(1-M_{0}^{2}\right) \frac{\partial^{2} p_{m}}{\partial x^{2}}+\frac{\partial^{2} p_{m}}{\partial y^{2}}-2 i k M_{0} \frac{\partial p_{m}}{\partial x}+\left[k^{2}-\left(\frac{m \pi}{W}\right)^{2}\right] p_{m}=0
$$


and a time dependence of the form $e^{i \omega t}$ has been assumed. At the source plane $(x=0)$, the acoustic pressure is assumed known

$$
p_{m}(0, y)=G_{m}(y), \quad m=0,1,2, \ldots \infty
$$

For the plane wave source used in the current investigation (i.e., $m=0$ ), this acoustic pressure becomes

$$
P_{0}(0, y)=p_{s}
$$

The locally-reacting wall impedance boundary condition, as presented by Myers, ${ }^{10}$ is

$$
\frac{\partial p_{m}}{\partial y}=i k\left(\frac{p_{m}}{\zeta}\right)+2 M_{0} \frac{\partial}{\partial x}\left(\frac{p_{m}}{\zeta}\right)+\frac{M_{0}^{2}}{i k} \frac{\partial^{2}}{\partial x^{2}}\left(\frac{p_{m}}{\zeta}\right)
$$

and the exit plane condition becomes

$$
\frac{\partial p_{m}}{\partial x}=-i k \frac{p_{m}}{\left(M_{0}+\zeta_{\text {exit }}\right)}
$$

Closed form solutions for test liner impedances that reproduce a known lower wall acoustic pressure distribution are available only for infinitely long ducts with uniform wall linings. Thus, a numerical procedure is needed to educe the test liner impedance. Equations (3) - (7) constitute a boundary-value problem that can be solved to uniquely determine the lower wall acoustic pressure, $p_{m}(x, 0)$, for a given test liner impedance (i.e., propagation mode). Conversely, if the lower wall acoustic pressure distribution is known (at a sufficient number of microphone locations), this boundary-value problem can be iteratively solved to uniquely determine the liner impedance that reproduces the known lower wall acoustic pressure distribution (i.e., impedance eduction mode). For the CDTR configuration, in which the liner is placed on the side wall, a similar derivation is used.

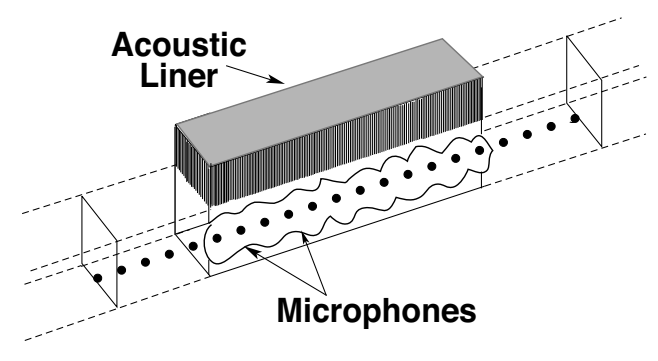

Figure 2. Sketch of GFIT with microphone array on wall opposite liner.

\title{
III. Optimization of GFIT Liner Length and Microphone Placements
}

\section{A. Results using Synthesized Data on Wall Opposite the Liner ( $y=0 \mathrm{~mm})$}

\begin{abstract}
S mentioned earlier, the first goal of the current investigation is to determine the efficacy of using the Grazing Flow AImpedance Tube (GFIT) microphone array to educe the impedances of variable length liners. For this portion of the study, the GFIT geometry is used, and 53 microphones are positioned along the spanwise centerline of the wall opposite the liner (lower wall for this duct, figure 2). First, the Q3D code described in the Analysis Section is used to calculate the acoustic pressure distribution throughout the duct. Equations (3) - (7) are used to compute the acoustic pressure amplitude and phase at each of the microphone locations based on the following input parameters:
\end{abstract}

1. Source frequency, 1000 or $3000 \mathrm{~Hz}$

2. Source plane amplitude, $130 \mathrm{~dB}$

3. Liner impedance, $\zeta_{\mathrm{set}}=1-i$ or $\zeta_{\mathrm{set}}=2+i$

4. Liner length, $L_{2}-L_{1}=51,102,203,406$ or $610 \mathrm{~mm}$

5. Liner leading edge location, $L_{1}$ (liner is centered in the $1016 \mathrm{~mm}$ test window) 
The resultant synthesized acoustic pressure data are then used as input to the Q3D code using the established impedance eduction process. This impedance eduction is initially conducted based on the exact output from the Q3D code when configured in propagation mode, to determine how well this procedure predicts the impedance of liners of reduced length based on synthesized data. Next, these synthesized acoustic pressure data are modified by the addition of random noise to simulate the effects of flow noise and acoustic pressure measurement uncertainty. The impedance is then educed with this randomized synthetic data, to determine how these uncertainties in the acoustic pressure data will translate to uncertainties in the impedances educed with the Q3D code. Finally, the educed impedance is compared with that initially input into the propagation code to determine how well the impedance eduction process functions.

Table 1 provides the results for 51 to $610 \mathrm{~mm}$-long liners placed in the GFIT with no flow. A comparison of the impedance for a given liner length, educed using 'ideal' data (i.e., no random noise added), against the impedance initially input into the propagation code can be used to evaluate the efficacy of using different liner lengths in the impedance eduction process. At the two frequencies of interest $(1000$ and $3000 \mathrm{~Hz})$, the educed impedances for the $610 \mathrm{~mm}$ liner are observed (table 1, all tables are found at end of paper) to match the known liner impedance (resistance and reactance) to within $0.0002 \rho c$ units. For the shorter liners, the error in the educed impedance increases slightly, but the results are still excellent. The corresponding Mach 0.3 results (see table 2) are nearly as good as those for no flow. In fact, the errors in educed resistance and reactance are all less than $0.01 \rho c$.

\section{B. Results using Synthesized Data with Random Scatter on Wall Opposite the Liner $(y=0 \mathbf{m m})$}

B ASED on the results above, the GFIT microphone array is clearly sufficient for impedance eduction for the limited B conditions investigated in the current study, as long as the input data (acoustic pressure profile) is devoid of measurement uncertainties. However, it is important to account for the amount of uncertainty that could be introduced into the eduction process based on potential measurement errors. For the purposes of this study, the uncertainty is assumed to be no greater than $\pm 0.5 \mathrm{~dB}$ and \pm 1.0 degree for any individual microphone used in this test rig. Thus, a uniform-distribution random number generator was used to determine what portion of this uncertainty to add to or subtract from the synthesized acoustic pressure at each microphone location. Two levels of data scatter $(\{ \pm 0.25 \mathrm{~dB}$, \pm 0.5 degree $\}$ and $\{ \pm 0.5 \mathrm{~dB}, \pm 1.0$ degree $\}$ ) were applied to the synthesized acoustic pressure data to investigate the effects of data scatter on the impedance eduction process. For each level of data scatter, impedance eductions were performed with the Q3D code at each test condition (frequency, Mach number, liner length, input liner impedance) for eleven trials (a different random number sequence was used for each trial) to provide the basis for small-sample statistical analysis ${ }^{11}$ of the results.

Tables 3 and 4 provide the educed impedance errors $\left(\zeta_{\mathrm{err}}=\theta_{\mathrm{err}}+i \chi_{\mathrm{err}}\right)$ for each condition, where $\theta_{\text {err }}$ and $\chi_{\mathrm{err}}$ are given by

$$
\theta_{\text {err }}=\left|\theta_{\mathrm{e}}-\theta_{\text {set }}\right| \text { and } \chi_{\text {err }}=\left|\chi_{\mathrm{e}}-\chi_{\text {set }}\right|
$$

In each of these and all successive tables, column 1 provides the length of the liner in millimeters. Column 2 provides the mean error in educed resistance based on synthesized acoustic pressure data with minimum random scatter included, $\theta_{\text {mean }}$. Column 3 provides the approximate $95 \%$ confidence estimate of the random uncertainty, ${ }^{11} \theta_{\text {unc }}$, for $\theta_{\text {err }}$, which indicates the interval given by $\theta_{\text {mean }} \pm \theta_{\text {unc }}$ will contain the true mean error with $95 \%$ confidence. Columns 4 and 5 provide similar information for the educed reactance error. Columns 6 through 9 provide the corresponding results based on synthesized acoustic pressure data with maximum random scatter included.

A number of conclusions can be drawn from these data, some more surprising than others. As expected, the errors in educed impedance increase with increases in the magnitude of random scatter that is added to the synthesized acoustic pressures at each microphone location. Educed impedance errors also tend to decrease with increasing liner length, as would be expected. However, there are a number of cases where the error is actually lowest for the $406 \mathrm{~mm}$ liner length. It should be noted that increases in the liner length result in corresponding decreases in the hardwall sections upstream and downstream of the liner. For this configuration, fewer measurements are acquired in the hardwall sections (the microphone locations are fixed for the GFIT), resulting in reduced resolution of the standing waves in these sections. (In the limit, if there are no measurements conducted in the hardwall sections, the current approach cannot be used, as the acoustic pressures measured in the liner section do not provide sufficient information to educe a unique liner impedance.) Thus, while the results for the longest $(610 \mathrm{~mm})$ liner are still excellent, the upward trend in errors indicate the optimum liner length for evaluation with the current GFIT microphone array is somewhere between 203 and $610 \mathrm{~mm}$. It should also be noted that the conclusions drawn from these data are not universal; i.e., the results for a particular condition $\left(\zeta_{\text {set }}, M_{0}, f\right.$ and liner length) can differ significantly from the 'norm.' This is affected by a 
number of parameters (e.g., duct geometry, mean flow profiles, exit impedance). As a result, similar analysis to that presented here should be considered for any specific conditions where the results are mission critical.

Figures 3 through 9 provide graphical depictions of the resistance error results for a number of conditions provided in tables 3 through 8 . In each of these figures, the mean resistance $\left(\theta_{\text {mean }}\right)$ and reactance $\left(\chi_{\text {mean }}\right)$ errors are used as figures of merit. These values are computed by taking the average of the resistance and reactance errors $\left(\theta_{\text {err }}, \chi_{\text {err }}\right)$ computed for each of the 11 trials. The results educed from synthesized data with no additional random scatter are not included in these figures, as the errors for these cases were virtually nonexistent. In each of these figures, red circles are used to depict mean errors computed from data with minimum random scatter included, and the red error bars provide the corresponding interval for the approximate $95 \%$ confidence estimate of the random uncertainty. Blue squares and error bars depict corresponding results computed from acoustic pressures with maximum random scatter included. Solid and open symbols are used to depict the mean resistance and reactance errors, respectively.

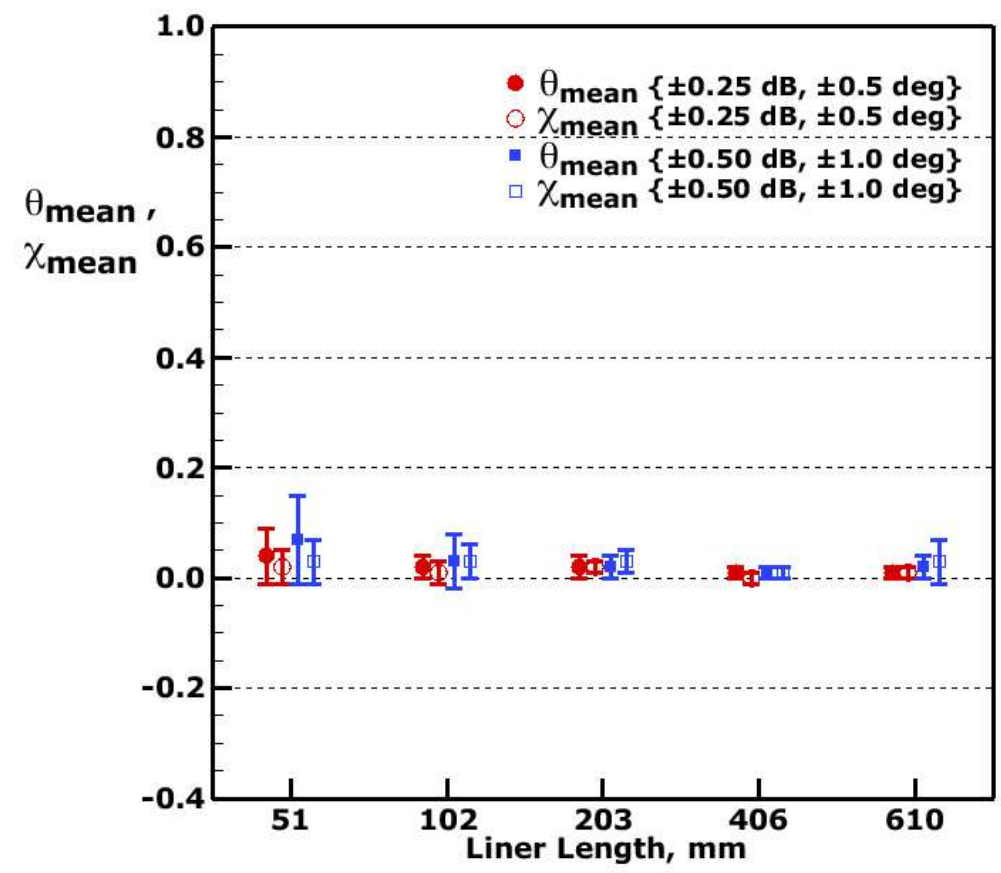

Figure 3. Mean resistance and reactance errors, with uncertainty limits, based on impedance eduction for microphones on GFIT wall opposite the liner, $1000 \mathrm{~Hz}, M_{0}=0.0, \zeta_{\text {set }}=1-i$, normalized by $\rho c$. Data taken from table 3-a.

Figures 3 through 6 are based on data from tables 3 and 4, which contain results computed from acoustic pressure data synthesized on the lower wall (opposite the liner). Figure 3 shows that for no flow, a $1000 \mathrm{~Hz}$ plane wave source, and a liner impedance of $\zeta_{\text {set }}=1-i, \theta_{\text {mean }}$ is quite small for each liner length. It is smallest (best) for a liner length of $406 \mathrm{~mm}$. However, the results change when the liner impedance is changed to $\zeta_{\mathrm{set}}=2+i$ (see figure 4 ). Although the minimum $\theta_{\text {mean }}$ computed from acoustic pressures with random scatter still (barely) occurs for the $406 \mathrm{~mm}$ liner, the values are generally noticeably larger. However, if the liner length is at least $203 \mathrm{~mm}$, these errors are acceptable.

Figures 4 and 5 show an effect of mean flow. As the mean flow is increased from $M_{0}=0.0$ to $M_{0}=0.3$, there are large increases in $\theta_{\text {mean }}$ for the two shortest liners, with less significant increases for the longer liners. If the Mach number is held constant at $M_{0}=0.3$, and the source frequency is increased from 1000 to $3000 \mathrm{~Hz}$ (figures 5 and 6), a marked decrease in $\theta_{\text {mean }}$ is observed for each of the liner lengths. Clearly, there is interaction among multiple parameters in determining $\theta_{\text {mean. }}$. However, it appears clear that liners with lengths less than $203 \mathrm{~mm}$ will require careful scrutiny. 


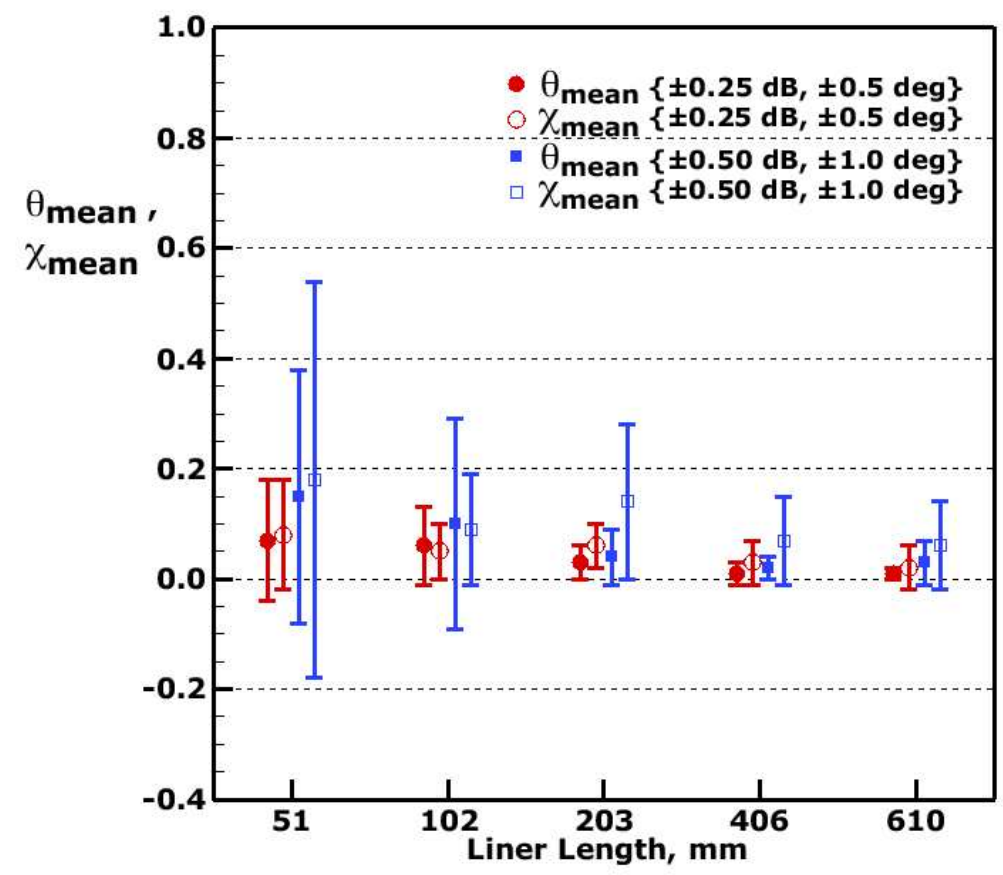

Figure 4. Mean resistance and reactance errors, with uncertainty limits, based on impedance eduction for microphones on GFIT wall opposite the liner, $1000 \mathrm{~Hz}, M_{0}=0.0, \zeta_{\text {set }}=2+i$, normalized by $\rho c$. Data taken from table 3-b.

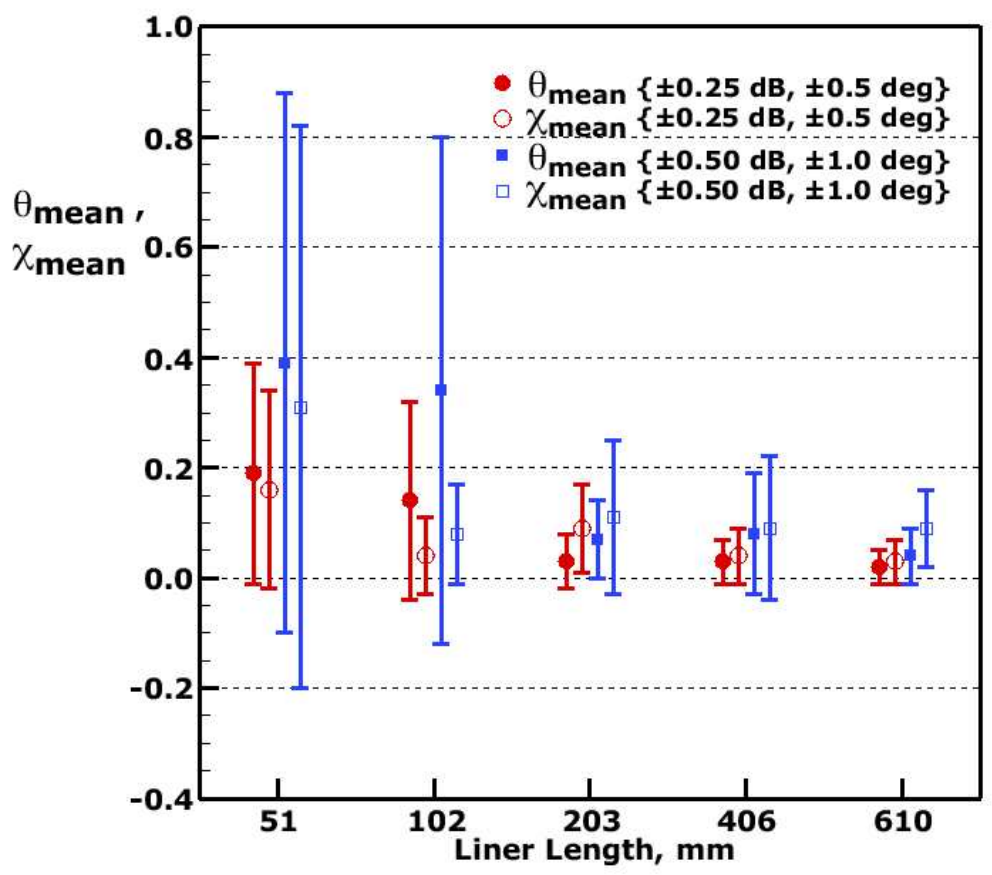

Figure 5. Mean resistance and reactance errors, with uncertainty limits, based on impedance eduction for microphones on GFIT wall opposite the liner, $1000 \mathrm{~Hz}, M_{0}=0.3, \zeta_{\mathrm{set}}=2+i$, normalized by $\rho c$. Data taken from table 3-d. 


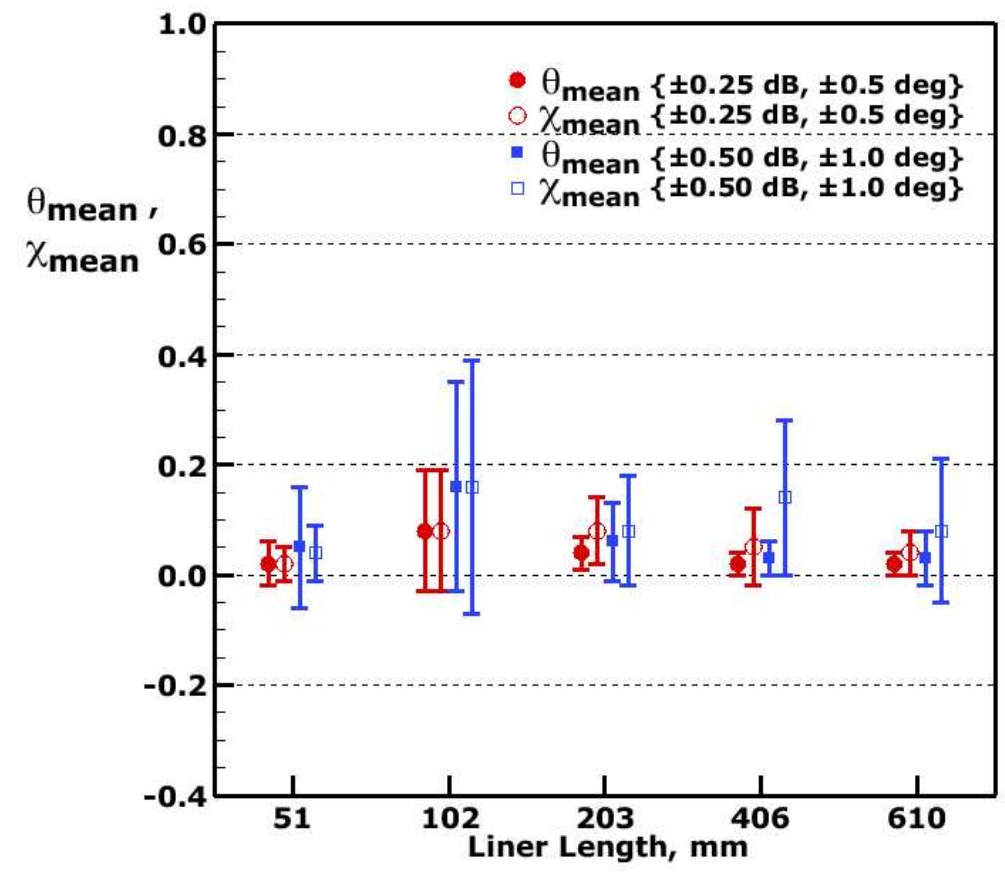

Figure 6. Mean resistance and reactance errors, with uncertainty limits, based on impedance eduction for microphones on GFIT wall opposite the liner, $3000 \mathrm{~Hz}, M_{0}=0.3, \zeta_{\text {set }}=2+i$, normalized by $\rho c$. Data taken from table 4-d.

C. Results using Synthesized Data with Random Scatter on Wall Adjacent to the Liner $(y=32 \mathrm{~mm}$ and $y=48 \mathbf{m m})$

THE results above indicate 53 microphones currently located on the lower wall of the GFIT (opposite the liner) can

be successfully used to educe impedances for liners at least $203 \mathrm{~mm}$ long. Tables 5-8, and figures 8 and 9 provide results based on acoustic pressures synthesized on the side wall adjacent to the liner, at heights of 32 and $48 \mathrm{~mm}$ from the lower wall. In general, the results for liners no less than $406 \mathrm{~mm}$ long remain acceptable. However, a comparison of figures 6,8 and 9 , in which the microphone array is successively moved from the lower wall $(y=0 \mathrm{~mm})$ to two heights ( $y=32 \mathrm{~mm}$ and $y=48 \mathrm{~mm}$ ) on the side wall (see figure 7), provide addition insight. Clearly, the results for the two shortest liners are significantly worse when the microphones are placed along the $y=32 \mathrm{~mm}$ height, which is the midpoint between the lower and upper walls. If a soft-wall mode in the liner section has a null at this height, this array would be expected to be less effective. However, the current investigation did not include a sufficient number of test conditions to properly evaluate whether this is the cause of the reduced quality for this microphone array placement. Regardless, it is clear that microphones should not be placed in a straight array along the vertical midpoint of the side wall.

\section{Optimization of CDTR Microphone Distribution for Impedance Eduction}

$\mathrm{T}$

HE second goal of the current investigation is to determine an appropriate microphone distribution on the lower wall of the Curved Duct Test Rig (CDTR) to support impedance eduction. Recall that $813 \mathrm{~mm}$-long liners form one or both side walls of the CDTR; thus, the lower wall is adjacent to at least one treated wall. The results of the previous sections, which demonstrated the suitability of using microphones placed on the GFIT wall adjacent to the liner for impedance eduction, provide encouragement that the placement of microphones on the adjacent wall should be acceptable.

Thirty-two microphones have been designated for impedance eduction in the CDTR. In this final portion of the current investigation, 100 possible microphone arrays were evaluated to determine the sensitivity of the impedance eduction process to the microphone locations. Each potential microphone array was randomly distributed along the 


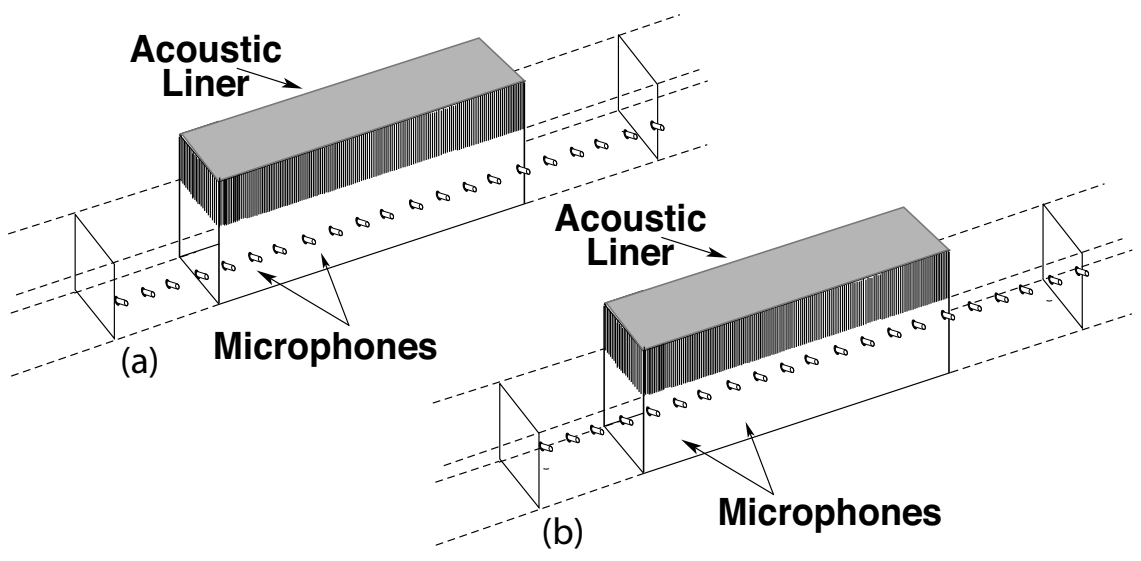

Figure 7. Sketch of GFIT with microphone arrays on wall adjacent to liner; (a) along $y=32 \mathbf{m m}$, and (b) along $y=48 \mathbf{m m}$.

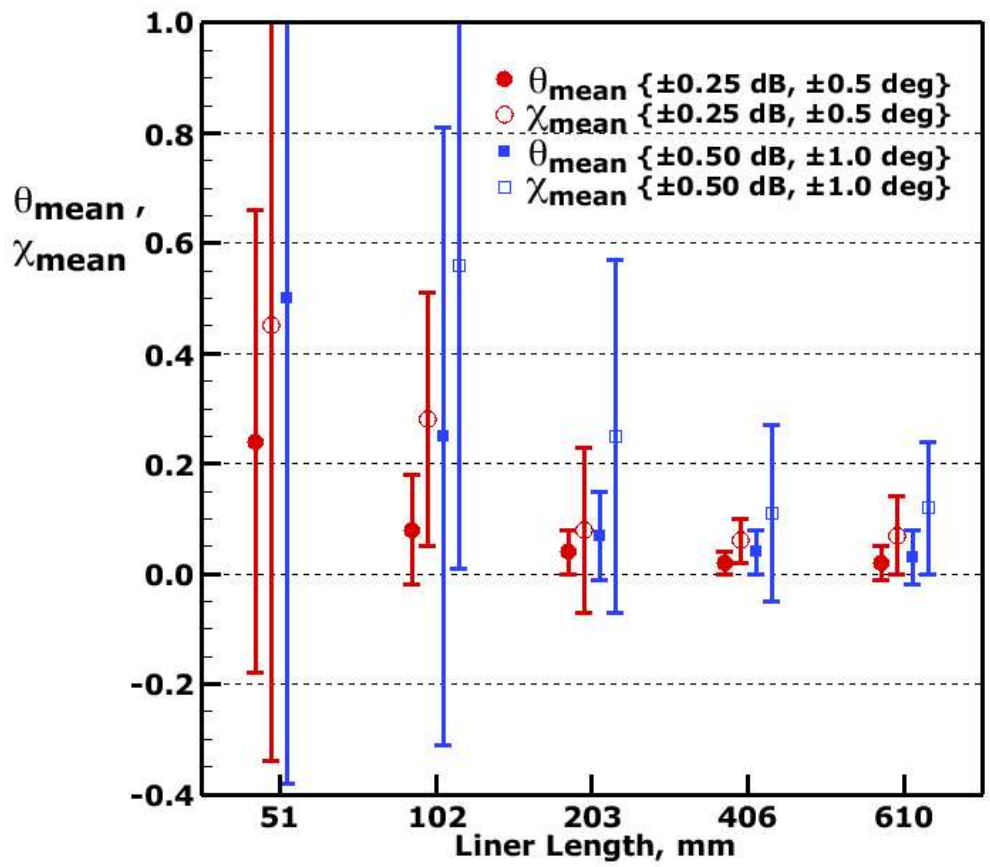

Figure 8. Mean resistance and reactance errors, with uncertainty limits, based on impedance eduction for microphones on GFIT wall $(y=32 \mathrm{~mm})$ adjacent to the liner, $3000 \mathrm{~Hz}, M_{0}=0.3$, $\zeta_{\text {set }}=2+i$, normalized by $\rho c$. Data taken from table 6-d. 


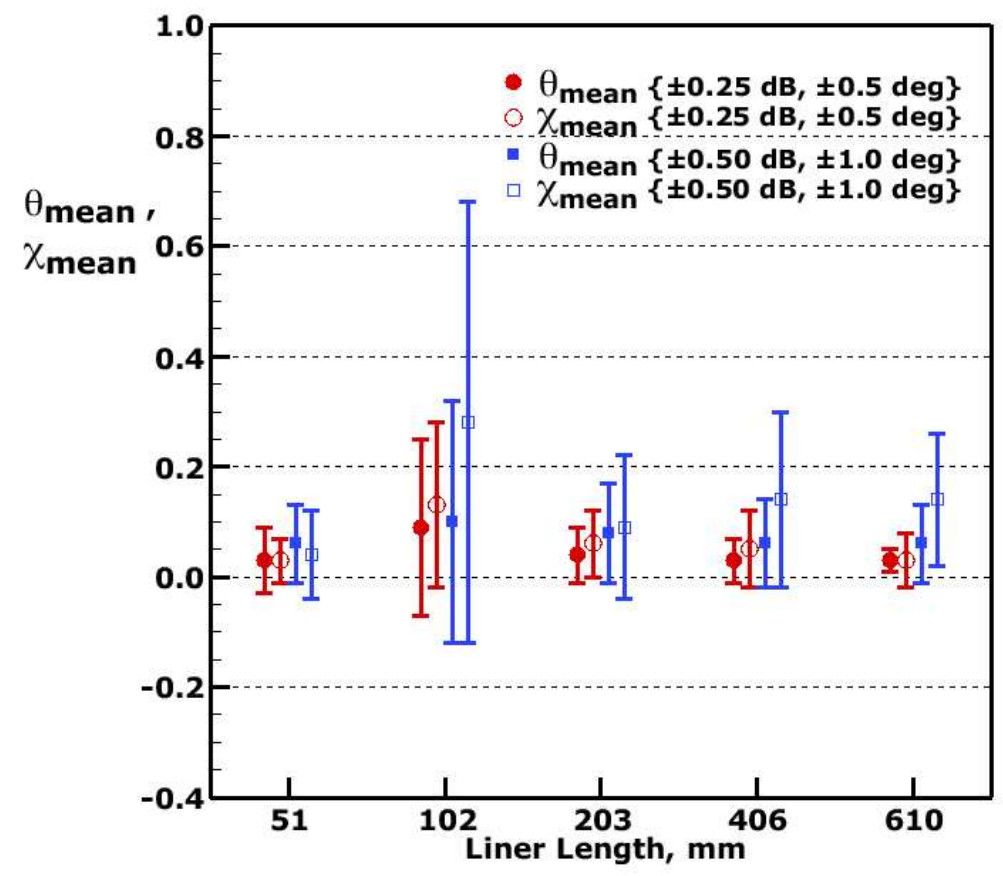

Figure 9. Mean resistance and reactance errors, with uncertainty limits, based on impedance eduction for microphones on GFIT wall $(y=48 \mathbf{~ m m})$ adjacent to the liner, $3000 \mathbf{H z}, M_{0}=0.3$, $\zeta_{\text {set }}=2+i$, normalized by $\rho c$. Data taken from table 8-d.

length of the lower wall according to the following constraints:

1. The first microphone is placed in the source plane

2. The last microphone is placed in the exit plane

3. The minimum axial spacing between adjacent microphones is $12.7 \mathrm{~mm}$

4. Each $38.1 \mathrm{~mm}$ axial portion of the duct contains at least one microphone

5. The microphone spanwise locations are randomly distributed

6. No microphone is placed within $12.7 \mathrm{~mm}$ of either side wall

For this portion of the study, the liner impedance was taken to be $\zeta_{\text {set }}=1-i$, the mean flow was $M_{0}=0.3$, and the plane wave source was set to $1000 \mathrm{~Hz}$ and $130 \mathrm{~dB}$.

For each potential microphone array, the Q3D code was again used in source mode to synthesize the acoustic pressures at each of the microphone locations. In a manner similar to that used above, minimum and maximum random scatter $(\{ \pm 0.25 \mathrm{~dB}, \pm 0.5 \mathrm{deg}\}$ and $\{ \pm 0.50 \mathrm{~dB}, \pm 1.0 \mathrm{deg}\})$ were successively added to the acoustic pressure at each microphone location. These data were then input to the Q3D code, configured in impedance eduction mode, and the liner impedances were educed. For all of these configurations, the educed resistance error never exceeded $0.09 \rho c$, and the educed reactance error never exceeded $0.06 \rho c$. Thus, at least for this test condition, the choice of microphone array distribution is not critical. The best microphone distribution, depicted in figure 10, produced an educed impedance of $\zeta_{\mathrm{e}}=1.00033-1.00214 i$. This microphone distribution was further evaluated for the following conditions:

1. Liner impedance: $\zeta_{\text {set }}=1-i, 2+i$ or $3-2 i$

2. Source frequency: 1000,2000 or $3000 \mathrm{~Hz}$

3. Uniform mean flow: $M_{0}=0.0,0.3$ or 0.5 


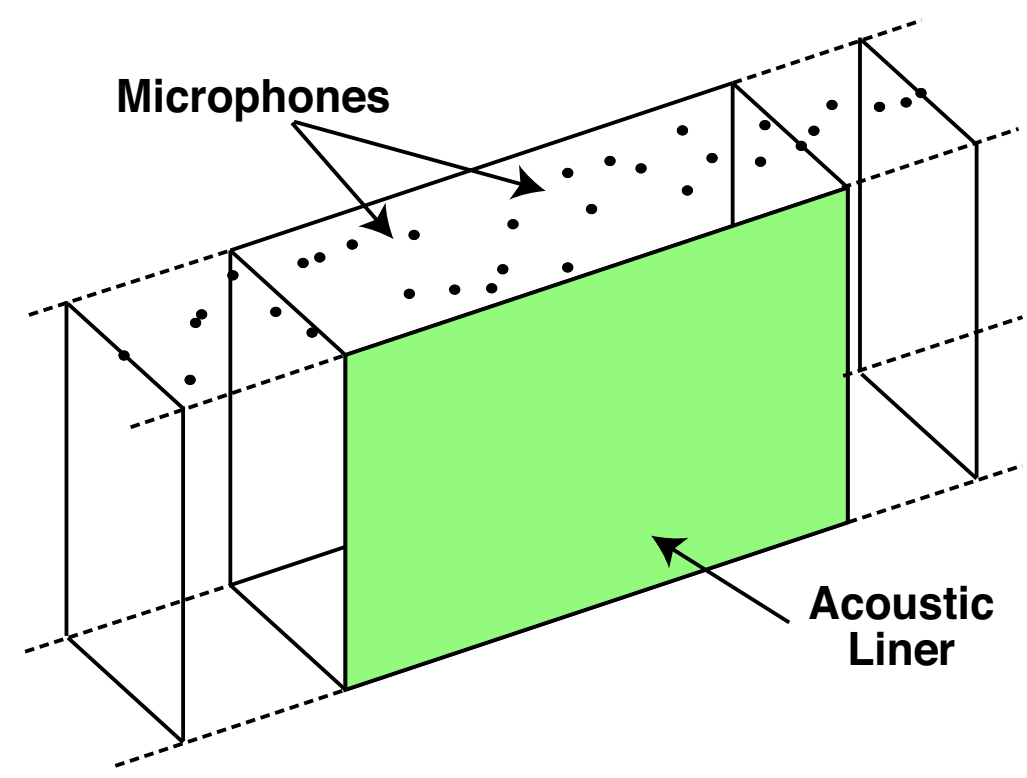

Figure 10. Optimized microphone distribution for CDTR wall adjacent to liner.

Each condition was evaluated with zero, minimum or maximum random scatter added to the synthesized acoustic pressures at each microphone location. The results of these computations are provided in table 9. Clearly, if the acoustic pressure data is devoid of measurement error, this microphone distribution provides sufficient data such that the Q3D code accurately educes the acoustic impedance of the liner. Since only one trial was performed for each of test conditions, uncertainty limits cannot be established. Regardless, errors up to $0.3 \rho c$ and $0.5 \rho c$ are observed for the acoustic pressures with minimum and maximum random scatter, respectively. Thus, while the majority of the results are acceptable, educed impedance errors are larger than desired for some of these conditions. Possible causes include:

1. Insufficient number of microphones (32) to resolve the higher-order mode effects in this duct

2. Constraints used in the microphone array design process

3. Insufficient number of evaluations to determine whether educed impedance errors are outliers

4. Insufficient number of microphones to resolve standing wave patterns in the hardwall sections

As mentioned earlier, a concurrent project is underway to develop a hybrid impedance eduction method for use with the CDTR. This method is based on a combination of modal and finite element approaches. Results achieved with each of the two impedance eduction methods will be compared to evaluate their respective strengths and weaknesses. The current plan is to use results from that investigation to influence decisions regarding where the additional 32 microphones are placed. When the hybrid approach is ready for detailed analysis, the methodology used in the current study will be used to aid in the determination of the final microphone distribution.

\section{Concluding Remarks}

$\mathrm{T}$ HE NASA Langley finite element code (Q3D) has been used to evaluate the effectiveness of the microphone distribution designed for the wall opposite the liner in the Langley Grazing Flow Impedance Tube (GFIT). This evaluation was conducted for a number of acoustic liner lengths being considered for testing in the GFIT. The microphone distribution was demonstrated to provide excellent results when the acoustic pressure at each microphone is devoid of measurement error. When minimum $\{ \pm 0.25 \mathrm{~dB}, \pm 0.5 \mathrm{deg}\}$ and maximum $\{ \pm 0.50 \mathrm{~dB}, \pm 1.0 \mathrm{deg}\}$ amounts of random scatter were added to the acoustic pressures, the microphone distribution was demonstrated to provide very good results for liners at least $203 \mathrm{~mm}$ in length.

Additional computations were performed with the microphone array moved to the GFIT wall adjacent to the liner, first along the vertical centerline, then in a row above the vertical centerline. In general, impedances educed with either of these arrays were acceptable, although not as good as observed for the wall opposite the liner. However, the results 
observed with the array on the vertical centerline demonstrated the greatest errors. Odd-numbered, higher-order modes will have a null along this line; thus, it is hypothesized that this might be the source of the increased error. The series of cases evaluated herein was not sufficient to resolve this question. Regardless, the results indicate an array on the wall adjacent to the acoustic liner can be successfully used for impedance eduction if placed off the wall centerline.

Finally, a procedure was defined for evaluating potential microphone distributions along the wall adjacent to the liner in the Langley Curved Duct Test Rig (CDTR). One hundred randomly distributed microphone arrays (within selected constraints) were evaluated, in which the microphones were distributed over the majority of the lower wall. Each of these arrays provided excellent results when the acoustic pressures were devoid of measurement error. The educed acoustic impedances generally remained acceptable when measurement error was added to the acoustic pressures, although some of the educed impedance errors were larger than desired. Regardless, this procedure appears to be appropriate for evaluating potential microphone distributions. Thus, when a concurrent study based on a modal analysis and finite element method hybrid approach is completed, an optimum microphone array will be designed for usage with either (Q3D or hybrid) approach to achieve increased impedance eduction fidelity with the CDTR.

\section{References}

\footnotetext{
${ }^{1}$ Armstrong, D.L., Beckemeyer, R.J., and Olsen, R.F., "Impedance Measurements of Acoustic Duct Liners With Grazing Flow," Paper presented at the 87th Meeting of the Acoustical Society of America, New York, NY, 1974.

${ }^{2}$ Watson, W.R., Tanner, S.E., and Parrott, T.L., "Optimization Method for Educing Variable-Impedance Liner Properties," AIAA Journal, Vol. 36, No. 1, 1998, pp. 18-23.

${ }^{3}$ Watson, W.R., Tracy, M.B., Jones, M.G. and Parrott, T.L., "Impedance Eduction in the Presence of Shear Flow," AIAA 2001-2236, "Proceedings of the 7th AIAA/CEAS Aeroacoustics Conference \& Exhibit," May, 2001.

${ }^{4}$ Jones, M.G., Watson, W.R., Tracy, M.B., and Parrott, T.L., "Comparison of Two Waveguide Methods for Educing Liner Impedance in Grazing Flow," AIAA Journal, Vol. 42, No. 2, 2004, pp.232-240.

${ }^{5}$ Watson, W.R., Jones, M.G. and Parrott, T.L., "A Quasi-3-D Theory for Impedance Eduction in Uniform Grazing Flow," AIAA 2005-2848, "Proceedings of the 11 th AIAA/CEAS Aeroacoustics Conference \& Exhibit," May, 2005.

${ }^{6}$ Jones, M.G., Parrott, T.L., and Watson, W.R., "Comparison of Acoustic Impedance Eduction Techniques for Locally-Reacting Liners," AIAA Paper 2003-3306, "Proceedings of the 9th AIAA/CEAS Aeroacoustics Conference \& Exhibit," May 12-14, 2003.

${ }^{7}$ Simonich, J. Narayanan, S., Morin, B. and Patrick, W., "Development and Quantification of an In-Situ Grazing Flow Impedance Measurement Technique," AIAA 2005-2848, "Proceedings of the 11th AIAA/CEAS Aeroacoustics Conference \& Exhibit," May, 2006.

${ }^{8}$ Jones, M.G., Watson, W.R., Parrott, T.L., and Smith, C.D., "Design and Evaluation of Modifications to the NASA Langley Flow Impedance Tube," AIAA Paper 2004-2837, "Proceedings of the 10th AIAA/CEAS Aeroacoustics Conference," May 10-12, 2004.

${ }^{9}$ Gerhold, C., Cabell, R. and Brown, M., "Development of an Experimental Rig for Investigation of Higher Order Modes in Ducts," AIAA 2006-2637, "Proceedings of the 12th AIAA/CEAS Aeroacoustics Conference \& Exhibit," May, 2006.

${ }^{10}$ Myers, M.K., "On the Acoustic Boundary Condition in the Presence of Flow," Journal of Sound and Vibration, Vol. 71, No. 3, 1980, pp.429-434.

${ }^{11}$ Coleman, H.W. and Steele, W.G., “Experimentation and Uncertainty Analysis for Engineers: Second Edition,” Wiley Inter-Science, 1999.
} 
Table 1. Impedances educed from synthesized acoustic pressures for selected liner lengths in the GFIT, at $M_{0}=0.0$, normalized by $\rho c$

\begin{tabular}{|c|c|c|c|c|c|c|c|c|}
\hline & \multicolumn{4}{|c|}{$f=1000 \mathrm{~Hz}$} & \multicolumn{4}{c|}{$f=3000 \mathrm{~Hz}$} \\
\hline Liner Length $(\mathrm{mm})$ & \multicolumn{2}{|c|}{$\zeta_{\text {set }}=1-i$} & \multicolumn{2}{c|}{$\zeta_{\text {set }}=2+i$} & \multicolumn{2}{c|}{$\zeta_{\text {set }}=1-i$} & \multicolumn{2}{c|}{$\zeta_{\text {set }}=2+i$} \\
\hline$L_{2}-L_{1}$ & $\theta_{\mathrm{e}}$ & $\chi_{\mathrm{e}}$ & $\theta_{\mathrm{e}}$ & $\chi_{\mathrm{e}}$ & $\theta_{\mathrm{e}}$ & $\chi_{\mathrm{e}}$ & $\theta_{\mathrm{e}}$ & $\chi_{\mathrm{e}}$ \\
\hline 51 & 0.9998 & -0.9999 & 2.0001 & 1.0013 & 1.0000 & -1.0000 & 2.0005 & 1.0001 \\
102 & 1.0001 & -1.0002 & 1.9999 & 0.9991 & 0.9999 & -0.9999 & 1.9992 & 1.0000 \\
203 & 1.0000 & -0.9999 & 2.0002 & 1.0002 & 0.9999 & -1.0000 & 2.0000 & 1.0000 \\
406 & 1.0000 & -1.0000 & 2.0000 & 1.0001 & 1.0000 & -1.0000 & 2.0000 & 1.0000 \\
610 & 1.0001 & -1.0000 & 2.0001 & 1.0002 & 1.0000 & -1.0000 & 1.9999 & 1.0000 \\
\hline
\end{tabular}

Table 2. Impedances educed from synthesized acoustic pressures for selected liner lengths in the GFIT, at $M_{0}=0.3$, normalized by $\rho c$

\begin{tabular}{|c|c|c|c|c|c|c|c|c|}
\hline & \multicolumn{4}{|c|}{$f=1000 \mathrm{~Hz}$} & \multicolumn{4}{c|}{$f=3000 \mathrm{~Hz}$} \\
\hline Liner Length $(\mathrm{mm})$ & \multicolumn{2}{|c|}{$\zeta_{\mathrm{set}}=1-i$} & \multicolumn{2}{c|}{$\zeta_{\mathrm{set}}=2+i$} & \multicolumn{2}{c|}{$\zeta_{\text {set }}=1-i$} & \multicolumn{2}{c|}{$\zeta_{\text {set }}=2+i$} \\
\hline$L_{2}-L_{1}$ & $\theta_{\mathrm{e}}$ & $\chi_{\mathrm{e}}$ & $\theta_{\mathrm{e}}$ & $\chi_{\mathrm{e}}$ & $\theta_{\mathrm{e}}$ & $\chi_{\mathrm{e}}$ & $\theta_{\mathrm{e}}$ & $\chi_{\mathrm{e}}$ \\
\hline 51 & 1.0004 & -0.9982 & 1.9994 & 0.9988 & 1.0000 & -0.9999 & 1.9997 & 0.9998 \\
102 & 1.0000 & -1.0008 & 1.9997 & 1.0003 & 0.9999 & -1.0001 & 2.0001 & 1.0001 \\
203 & 1.0000 & -1.0005 & 1.9994 & 0.9985 & 1.0000 & -1.0000 & 2.0000 & 0.9997 \\
406 & 0.9999 & -1.0002 & 2.0002 & 1.0001 & 1.0000 & -1.0000 & 2.0000 & 1.0001 \\
610 & 1.0000 & -1.0001 & 2.0001 & 1.0002 & 1.0000 & -1.0000 & 2.0000 & 1.0001 \\
\hline
\end{tabular}


Table 3. Errors in impedances educed from synthesized acoustic pressures with random data scatter on the GFIT wall opposite the liner, normalized by $\rho c(y=0 \mathrm{~mm}, 1000 \mathrm{~Hz}$ source $)$

(a) $\zeta_{\text {set }}=1-i, M_{0}=0.0$

\begin{tabular}{|c|c|c|c|c|c|c|c|c|}
\hline & \multicolumn{3}{|c|}{ $\pm 0.25 \mathrm{~dB}$ and $\pm 0.5 \mathrm{deg}$} & \multicolumn{4}{c|}{ $\pm 0.5 \mathrm{~dB}$ and $\pm 1.0 \mathrm{deg}$} \\
\hline Liner Length, $\mathrm{mm}$ & $\theta_{\text {mean }}$ & $\theta_{\text {unc }}$ & $\chi_{\text {mean }}$ & $\chi_{\text {unc }}$ & $\theta_{\text {mean }}$ & $\theta_{\text {unc }}$ & $\chi_{\text {mean }}$ & $\chi_{\text {unc }}$ \\
\hline 51 & 0.04 & 0.05 & 0.02 & 0.03 & 0.07 & 0.08 & 0.03 & 0.04 \\
102 & 0.02 & 0.02 & 0.01 & 0.02 & 0.03 & 0.05 & 0.03 & 0.03 \\
203 & 0.02 & 0.02 & 0.02 & 0.01 & 0.02 & 0.02 & 0.03 & 0.02 \\
406 & 0.01 & 0.01 & 0.00 & 0.01 & 0.01 & 0.01 & 0.01 & 0.01 \\
610 & 0.01 & 0.01 & 0.01 & 0.01 & 0.02 & 0.02 & 0.03 & 0.04 \\
\hline
\end{tabular}

(b) $\zeta_{\text {set }}=2+i, M_{0}=0.0$

\begin{tabular}{|c|c|c|c|c|c|c|c|c|}
\hline & \multicolumn{3}{|c|}{ $\pm 0.25 \mathrm{~dB}$ and $\pm 0.5 \mathrm{deg}$} & \multicolumn{4}{c|}{ $\pm 0.5 \mathrm{~dB}$ and $\pm 1.0 \mathrm{deg}$} \\
\hline Liner Length, mm & $\theta_{\text {mean }}$ & $\theta_{\text {unc }}$ & $\chi_{\text {mean }}$ & $\chi_{\text {unc }}$ & $\theta_{\text {mean }}$ & $\theta_{\text {unc }}$ & $\chi_{\text {mean }}$ & $\chi_{\text {unc }}$ \\
\hline 51 & 0.07 & 0.11 & 0.08 & 0.10 & 0.15 & 0.23 & 0.18 & 0.36 \\
102 & 0.06 & 0.07 & 0.05 & 0.05 & 0.10 & 0.19 & 0.09 & 0.10 \\
203 & 0.03 & 0.03 & 0.06 & 0.04 & 0.04 & 0.05 & 0.14 & 0.14 \\
406 & 0.01 & 0.02 & 0.03 & 0.04 & 0.02 & 0.02 & 0.07 & 0.08 \\
610 & 0.01 & 0.01 & 0.02 & 0.04 & 0.03 & 0.04 & 0.06 & 0.08 \\
\hline
\end{tabular}

(c) $\zeta_{\text {set }}=1-i, M_{0}=0.3$

\begin{tabular}{|c|c|c|c|c|c|c|c|c|}
\hline & \multicolumn{3}{|c|}{ $\pm 0.25 \mathrm{~dB}$ and $\pm 0.5 \mathrm{deg}$} & \multicolumn{4}{c|}{ $\pm 0.5 \mathrm{~dB}$ and $\pm 1.0 \mathrm{deg}$} \\
\hline Liner Length, mm & $\theta_{\text {mean }}$ & $\theta_{\text {unc }}$ & $\chi_{\text {mean }}$ & $\chi_{\text {unc }}$ & $\theta_{\text {mean }}$ & $\theta_{\text {unc }}$ & $\chi_{\text {mean }}$ & $\chi_{\text {unc }}$ \\
\hline 51 & 0.10 & 0.10 & 0.06 & 0.10 & 0.20 & 0.21 & 0.11 & 0.12 \\
102 & 0.03 & 0.04 & 0.04 & 0.05 & 0.07 & 0.10 & 0.08 & 0.13 \\
203 & 0.02 & 0.03 & 0.02 & 0.03 & 0.03 & 0.03 & 0.05 & 0.08 \\
406 & 0.01 & 0.01 & 0.02 & 0.03 & 0.01 & 0.02 & 0.05 & 0.05 \\
610 & 0.01 & 0.01 & 0.01 & 0.02 & 0.01 & 0.02 & 0.03 & 0.04 \\
\hline
\end{tabular}

(d) $\zeta_{\text {set }}=2+i, M_{0}=0.3$

\begin{tabular}{|c|c|c|c|c|c|c|c|c|}
\hline & \multicolumn{3}{|c|}{ $\pm 0.25 \mathrm{~dB}$ and $\pm 0.5 \mathrm{deg}$} & \multicolumn{3}{c|}{ $\pm 0.5 \mathrm{~dB}$ and $\pm 1.0 \mathrm{deg}$} \\
\hline Liner Length, $\mathrm{mm}$ & $\theta_{\text {mean }}$ & $\theta_{\text {unc }}$ & $\chi_{\text {mean }}$ & $\chi_{\text {unc }}$ & $\theta_{\text {mean }}$ & $\theta_{\text {unc }}$ & $\chi_{\text {mean }}$ & $\chi_{\text {unc }}$ \\
\hline 51 & 0.19 & 0.20 & 0.16 & 0.18 & 0.39 & 0.49 & 0.31 & 0.51 \\
102 & 0.14 & 0.18 & 0.04 & 0.07 & 0.34 & 0.46 & 0.08 & 0.09 \\
203 & 0.03 & 0.05 & 0.09 & 0.08 & 0.07 & 0.07 & 0.11 & 0.14 \\
406 & 0.03 & 0.04 & 0.04 & 0.05 & 0.08 & 0.11 & 0.09 & 0.13 \\
610 & 0.02 & 0.03 & 0.03 & 0.04 & 0.04 & 0.05 & 0.09 & 0.07 \\
\hline
\end{tabular}


Table 4. Errors in impedances educed from synthesized acoustic pressures with random data scatter on the GFIT wall opposite the liner, normalized by $\rho c(y=0 \mathbf{m m}, 3000 \mathrm{~Hz}$ source)

(a) $\zeta_{\text {set }}=1-i, M_{0}=0.0$

\begin{tabular}{|c|c|c|c|c|c|c|c|c|}
\hline & \multicolumn{3}{|c|}{ $\pm 0.25 \mathrm{~dB}$ and $\pm 0.5 \mathrm{deg}$} & \multicolumn{4}{c|}{ $\pm 0.5 \mathrm{~dB}$ and $\pm 1.0 \mathrm{deg}$} \\
\hline Liner Length, mm & $\theta_{\text {mean }}$ & $\theta_{\text {unc }}$ & $\chi_{\text {mean }}$ & $\chi_{\text {unc }}$ & $\theta_{\text {mean }}$ & $\theta_{\text {unc }}$ & $\chi_{\text {mean }}$ & $\chi_{\text {unc }}$ \\
\hline 51 & 0.02 & 0.03 & 0.01 & 0.01 & 0.04 & 0.05 & 0.01 & 0.02 \\
102 & 0.02 & 0.02 & 0.01 & 0.01 & 0.02 & 0.04 & 0.01 & 0.02 \\
203 & 0.01 & 0.01 & 0.01 & 0.01 & 0.01 & 0.02 & 0.02 & 0.04 \\
406 & 0.00 & 0.01 & 0.00 & 0.01 & 0.00 & 0.01 & 0.01 & 0.01 \\
610 & 0.01 & 0.01 & 0.01 & 0.01 & 0.01 & 0.01 & 0.01 & 0.02 \\
\hline
\end{tabular}

(b) $\zeta_{\text {set }}=2+i, M_{0}=0.0$

\begin{tabular}{|c|c|c|c|c|c|c|c|c|}
\hline & \multicolumn{3}{|c|}{ $\pm 0.25 \mathrm{~dB}$ and $\pm 0.5 \mathrm{deg}$} & \multicolumn{4}{c|}{ $\pm 0.5 \mathrm{~dB}$ and $\pm 1.0 \mathrm{deg}$} \\
\hline Liner Length, mm & $\theta_{\text {mean }}$ & $\theta_{\text {unc }}$ & $\chi_{\text {mean }}$ & $\chi_{\text {unc }}$ & $\theta_{\text {mean }}$ & $\theta_{\text {unc }}$ & $\chi_{\text {mean }}$ & $\chi_{\text {unc }}$ \\
\hline 51 & 0.04 & 0.02 & 0.01 & 0.02 & 0.05 & 0.07 & 0.04 & 0.06 \\
102 & 0.06 & 0.06 & 0.03 & 0.04 & 0.14 & 0.10 & 0.06 & 0.06 \\
203 & 0.03 & 0.05 & 0.03 & 0.03 & 0.08 & 0.10 & 0.07 & 0.11 \\
406 & 0.03 & 0.03 & 0.05 & 0.06 & 0.04 & 0.05 & 0.10 & 0.13 \\
610 & 0.03 & 0.03 & 0.04 & 0.04 & 0.04 & 0.05 & 0.07 & 0.09 \\
\hline
\end{tabular}

(c) $\zeta_{\text {set }}=1-i, M_{0}=0.3$

\begin{tabular}{|c|c|c|c|c|c|c|c|c|}
\hline & \multicolumn{3}{|c|}{ $\pm 0.25 \mathrm{~dB}$ and $\pm 0.5 \mathrm{deg}$} & \multicolumn{4}{c|}{ $\pm 0.5 \mathrm{~dB}$ and $\pm 1.0 \mathrm{deg}$} \\
\hline Liner Length, mm & $\theta_{\text {mean }}$ & $\theta_{\text {unc }}$ & $\chi_{\text {mean }}$ & $\chi_{\text {unc }}$ & $\theta_{\text {mean }}$ & $\theta_{\text {unc }}$ & $\chi_{\text {mean }}$ & $\chi_{\text {unc }}$ \\
\hline 51 & 0.02 & 0.02 & 0.01 & 0.01 & 0.03 & 0.04 & 0.02 & 0.02 \\
102 & 0.01 & 0.01 & 0.02 & 0.02 & 0.01 & 0.01 & 0.04 & 0.06 \\
203 & 0.00 & 0.00 & 0.00 & 0.00 & 0.01 & 0.01 & 0.01 & 0.01 \\
406 & 0.00 & 0.00 & 0.00 & 0.00 & 0.01 & 0.01 & 0.00 & 0.01 \\
610 & 0.01 & 0.01 & 0.00 & 0.00 & 0.01 & 0.02 & 0.01 & 0.01 \\
\hline
\end{tabular}

(d) $\zeta_{\text {set }}=2+i, M_{0}=0.3$

\begin{tabular}{|c|c|c|c|c|c|c|c|c|}
\hline & \multicolumn{3}{|c|}{ $\pm 0.25 \mathrm{~dB}$ and $\pm 0.5 \mathrm{deg}$} & \multicolumn{4}{c|}{ $\pm 0.5 \mathrm{~dB}$ and $\pm 1.0 \mathrm{deg}$} \\
\hline Liner Length, mm & $\theta_{\text {mean }}$ & $\theta_{\text {unc }}$ & $\chi_{\text {mean }}$ & $\chi_{\text {unc }}$ & $\theta_{\text {mean }}$ & $\theta_{\text {unc }}$ & $\chi_{\text {mean }}$ & $\chi_{\text {unc }}$ \\
\hline 51 & 0.02 & 0.04 & 0.02 & 0.03 & 0.05 & 0.11 & 0.04 & 0.05 \\
102 & 0.08 & 0.11 & 0.08 & 0.11 & 0.16 & 0.19 & 0.16 & 0.23 \\
203 & 0.04 & 0.03 & 0.08 & 0.06 & 0.06 & 0.07 & 0.08 & 0.10 \\
406 & 0.02 & 0.02 & 0.05 & 0.07 & 0.03 & 0.03 & 0.14 & 0.14 \\
610 & 0.02 & 0.02 & 0.04 & 0.04 & 0.03 & 0.05 & 0.08 & 0.13 \\
\hline
\end{tabular}


Table 5. Errors in impedances educed from synthesized acoustic pressures with random data scatter on the GFIT side wall, normalized by $\rho c(y=32 \mathrm{~mm}, 1000 \mathrm{~Hz}$ source $)$

(a) $\zeta_{\text {set }}=1-i, M_{0}=0.0$

\begin{tabular}{|c|c|c|c|c|c|c|c|c|}
\hline & \multicolumn{3}{|c|}{ $\pm 0.25 \mathrm{~dB}$ and $\pm 0.5 \mathrm{deg}$} & \multicolumn{4}{c|}{ $\pm 0.5 \mathrm{~dB}$ and $\pm 1.0 \mathrm{deg}$} \\
\hline Liner Length, mm & $\theta_{\text {mean }}$ & $\theta_{\text {unc }}$ & $\chi_{\text {mean }}$ & $\chi_{\text {unc }}$ & $\theta_{\text {mean }}$ & $\theta_{\text {unc }}$ & $\chi_{\text {mean }}$ & $\chi_{\text {unc }}$ \\
\hline 51 & 0.03 & 0.05 & 0.02 & 0.02 & 0.09 & 0.12 & 0.04 & 0.05 \\
102 & 0.02 & 0.02 & 0.02 & 0.02 & 0.04 & 0.05 & 0.04 & 0.05 \\
203 & 0.01 & 0.01 & 0.02 & 0.02 & 0.02 & 0.03 & 0.03 & 0.04 \\
406 & 0.01 & 0.01 & 0.01 & 0.01 & 0.01 & 0.01 & 0.01 & 0.02 \\
610 & 0.01 & 0.01 & 0.01 & 0.02 & 0.01 & 0.01 & 0.03 & 0.04 \\
\hline
\end{tabular}

(b) $\zeta_{\text {set }}=2+i, M_{0}=0.0$

\begin{tabular}{|c|c|c|c|c|c|c|c|c|}
\hline & \multicolumn{3}{|c|}{ $\pm 0.25 \mathrm{~dB}$ and $\pm 0.5 \mathrm{deg}$} & \multicolumn{4}{c|}{ $\pm 0.5 \mathrm{~dB}$ and $\pm 1.0 \mathrm{deg}$} \\
\hline Liner Length, mm & $\theta_{\text {mean }}$ & $\theta_{\text {unc }}$ & $\chi_{\text {mean }}$ & $\chi_{\text {unc }}$ & $\theta_{\text {mean }}$ & $\theta_{\text {unc }}$ & $\chi_{\text {mean }}$ & $\chi_{\text {unc }}$ \\
\hline 51 & 0.07 & 0.09 & 0.11 & 0.13 & 0.21 & 0.27 & 0.20 & 0.26 \\
102 & 0.07 & 0.07 & 0.05 & 0.07 & 0.12 & 0.17 & 0.08 & 0.11 \\
203 & 0.01 & 0.04 & 0.07 & 0.06 & 0.03 & 0.04 & 0.08 & 0.11 \\
406 & 0.02 & 0.02 & 0.03 & 0.04 & 0.03 & 0.03 & 0.05 & 0.07 \\
610 & 0.02 & 0.02 & 0.03 & 0.03 & 0.03 & 0.06 & 0.07 & 0.08 \\
\hline
\end{tabular}

(c) $\zeta_{\text {set }}=1-i, M_{0}=0.3$

\begin{tabular}{|c|c|c|c|c|c|c|c|c|}
\hline & \multicolumn{3}{|c|}{ $\pm 0.25 \mathrm{~dB}$ and $\pm 0.5 \mathrm{deg}$} & \multicolumn{4}{c|}{ $\pm 0.5 \mathrm{~dB}$ and $\pm 1.0 \mathrm{deg}$} \\
\hline Liner Length, mm & $\theta_{\text {mean }}$ & $\theta_{\text {unc }}$ & $\chi_{\text {mean }}$ & $\chi_{\text {unc }}$ & $\theta_{\text {mean }}$ & $\theta_{\text {unc }}$ & $\chi_{\text {mean }}$ & $\chi_{\text {unc }}$ \\
\hline 51 & 0.10 & 0.12 & 0.05 & 0.06 & 0.19 & 0.17 & 0.11 & 0.19 \\
102 & 0.05 & 0.06 & 0.07 & 0.06 & 0.09 & 0.14 & 0.12 & 0.12 \\
203 & 0.02 & 0.02 & 0.03 & 0.03 & 0.04 & 0.04 & 0.05 & 0.06 \\
406 & 0.01 & 0.01 & 0.02 & 0.03 & 0.01 & 0.02 & 0.05 & 0.05 \\
610 & 0.01 & 0.01 & 0.01 & 0.02 & 0.01 & 0.01 & 0.03 & 0.04 \\
\hline
\end{tabular}

(d) $\zeta_{\text {set }}=2+i, M_{0}=0.3$

\begin{tabular}{|c|c|c|c|c|c|c|c|c|}
\hline & \multicolumn{3}{|c|}{ $\pm 0.25 \mathrm{~dB}$ and $\pm 0.5 \mathrm{deg}$} & \multicolumn{4}{c|}{ $\pm 0.5 \mathrm{~dB}$ and $\pm 1.0 \mathrm{deg}$} \\
\hline Liner Length, mm & $\theta_{\text {mean }}$ & $\theta_{\text {unc }}$ & $\chi_{\text {mean }}$ & $\chi_{\text {unc }}$ & $\theta_{\text {mean }}$ & $\theta_{\text {unc }}$ & $\chi_{\text {mean }}$ & $\chi_{\text {unc }}$ \\
\hline 51 & 0.15 & 0.26 & 0.15 & 0.19 & 0.19 & 0.28 & 0.40 & 0.58 \\
102 & 0.16 & 0.19 & 0.05 & 0.06 & 0.40 & 0.53 & 0.10 & 0.13 \\
203 & 0.03 & 0.03 & 0.07 & 0.09 & 0.08 & 0.10 & 0.17 & 0.23 \\
406 & 0.04 & 0.05 & 0.03 & 0.04 & 0.07 & 0.10 & 0.08 & 0.09 \\
610 & 0.03 & 0.03 & 0.03 & 0.04 & 0.06 & 0.06 & 0.09 & 0.08 \\
\hline
\end{tabular}


Table 6. Errors in impedances educed from synthesized acoustic pressures with random data scatter on the GFIT side wall, normalized by $\rho c(y=32 \mathrm{~mm}, \mathbf{3 0 0 0} \mathrm{Hz}$ source $)$

(a) $\zeta_{\text {set }}=1-i, M_{0}=0.0$

\begin{tabular}{|c|c|c|c|c|c|c|c|c|}
\hline & \multicolumn{3}{|c|}{ $\pm 0.25 \mathrm{~dB}$ and $\pm 0.5 \mathrm{deg}$} & \multicolumn{4}{c|}{ $\pm 0.5 \mathrm{~dB}$ and $\pm 1.0 \mathrm{deg}$} \\
\hline Liner Length, mm & $\theta_{\text {mean }}$ & $\theta_{\text {unc }}$ & $\chi_{\text {mean }}$ & $\chi_{\text {unc }}$ & $\theta_{\text {mean }}$ & $\theta_{\text {unc }}$ & $\chi_{\text {mean }}$ & $\chi_{\text {unc }}$ \\
\hline 51 & 0.03 & 0.03 & 0.04 & 0.08 & 0.07 & 0.07 & 0.09 & 0.09 \\
102 & 0.01 & 0.01 & 0.04 & 0.04 & 0.04 & 0.04 & 0.09 & 0.09 \\
203 & 0.01 & 0.01 & 0.00 & 0.01 & 0.01 & 0.02 & 0.01 & 0.01 \\
406 & 0.01 & 0.01 & 0.01 & 0.01 & 0.02 & 0.01 & 0.01 & 0.01 \\
610 & 0.01 & 0.01 & 0.01 & 0.01 & 0.01 & 0.01 & 0.01 & 0.01 \\
\hline
\end{tabular}

(b) $\zeta_{\text {set }}=2+i, M_{0}=0.0$

\begin{tabular}{|c|c|c|c|c|c|c|c|c|}
\hline & \multicolumn{3}{|c|}{ $\pm 0.25 \mathrm{~dB}$ and $\pm 0.5 \mathrm{deg}$} & \multicolumn{4}{c|}{ $\pm 0.5 \mathrm{~dB}$ and $\pm 1.0 \mathrm{deg}$} \\
\hline Liner Length, mm & $\theta_{\text {mean }}$ & $\theta_{\text {unc }}$ & $\chi_{\text {mean }}$ & $\chi_{\text {unc }}$ & $\theta_{\text {mean }}$ & $\theta_{\text {unc }}$ & $\chi_{\text {mean }}$ & $\chi_{\text {unc }}$ \\
\hline 51 & 0.32 & 0.51 & 0.15 & 0.20 & 0.83 & 1.37 & 0.43 & 0.72 \\
102 & 0.08 & 0.10 & 0.15 & 0.26 & 0.35 & 0.32 & 0.54 & 0.56 \\
203 & 0.04 & 0.04 & 0.12 & 0.11 & 0.06 & 0.09 & 0.16 & 0.21 \\
406 & 0.01 & 0.01 & 0.04 & 0.06 & 0.03 & 0.04 & 0.11 & 0.15 \\
610 & 0.02 & 0.02 & 0.05 & 0.06 & 0.02 & 0.04 & 0.09 & 0.09 \\
\hline
\end{tabular}

(c) $\zeta_{\text {set }}=1-i, M_{0}=0.3$

\begin{tabular}{|c|c|c|c|c|c|c|c|c|}
\hline & \multicolumn{3}{|c|}{ $\pm 0.25 \mathrm{~dB}$ and $\pm 0.5 \mathrm{deg}$} & \multicolumn{4}{c|}{ $\pm 0.5 \mathrm{~dB}$ and $\pm 1.0 \mathrm{deg}$} \\
\hline Liner Length, mm & $\theta_{\text {mean }}$ & $\theta_{\text {unc }}$ & $\chi_{\text {mean }}$ & $\chi_{\text {unc }}$ & $\theta_{\text {mean }}$ & $\theta_{\text {unc }}$ & $\chi_{\text {mean }}$ & $\chi_{\text {unc }}$ \\
\hline 51 & 0.20 & 0.14 & 0.15 & 0.15 & 0.28 & 0.46 & 0.31 & 0.37 \\
102 & 0.07 & 0.10 & 0.03 & 0.04 & 0.13 & 0.16 & 0.03 & 0.06 \\
203 & 0.02 & 0.01 & 0.01 & 0.02 & 0.03 & 0.04 & 0.02 & 0.03 \\
406 & 0.01 & 0.01 & 0.01 & 0.01 & 0.02 & 0.02 & 0.01 & 0.02 \\
610 & 0.01 & 0.01 & 0.01 & 0.01 & 0.01 & 0.02 & 0.01 & 0.02 \\
\hline
\end{tabular}

(d) $\zeta_{\text {set }}=2+i, M_{0}=0.3$

\begin{tabular}{|c|c|c|c|c|c|c|c|c|}
\hline & \multicolumn{3}{|c|}{ $\pm 0.25 \mathrm{~dB}$ and $\pm 0.5 \mathrm{deg}$} & \multicolumn{3}{c|}{ $\pm 0.5 \mathrm{~dB}$ and $\pm 1.0 \mathrm{deg}$} \\
\hline Liner Length, $\mathrm{mm}$ & $\theta_{\text {mean }}$ & $\theta_{\text {unc }}$ & $\chi_{\text {mean }}$ & $\chi_{\text {unc }}$ & $\theta_{\text {mean }}$ & $\theta_{\text {unc }}$ & $\chi_{\text {mean }}$ & $\chi_{\text {unc }}$ \\
\hline 51 & 0.24 & 0.42 & 0.45 & 0.79 & 0.50 & 0.88 & 1.10 & 2.51 \\
102 & 0.08 & 0.10 & 0.28 & 0.23 & 0.25 & 0.56 & 0.56 & 0.55 \\
203 & 0.04 & 0.04 & 0.08 & 0.15 & 0.07 & 0.08 & 0.25 & 0.32 \\
406 & 0.02 & 0.02 & 0.06 & 0.04 & 0.04 & 0.04 & 0.11 & 0.16 \\
610 & 0.02 & 0.03 & 0.07 & 0.07 & 0.03 & 0.05 & 0.12 & 0.12 \\
\hline
\end{tabular}


Table 7. Errors in impedances educed from synthesized acoustic pressures with random data scatter on the GFIT side wall, normalized by $\rho c(y=48 \mathrm{~mm}, 1000 \mathrm{~Hz}$ source $)$

(a) $\zeta_{\text {set }}=1-i, M_{0}=0.0$

\begin{tabular}{|c|c|c|c|c|c|c|c|c|}
\hline & \multicolumn{3}{|c|}{ $\pm 0.25 \mathrm{~dB}$ and $\pm 0.5 \mathrm{deg}$} & \multicolumn{4}{c|}{ $\pm 0.5 \mathrm{~dB}$ and $\pm 1.0 \mathrm{deg}$} \\
\hline Liner Length, mm & $\theta_{\text {mean }}$ & $\theta_{\text {unc }}$ & $\chi_{\text {mean }}$ & $\chi_{\text {unc }}$ & $\theta_{\text {mean }}$ & $\theta_{\text {unc }}$ & $\chi_{\text {mean }}$ & $\chi_{\text {unc }}$ \\
\hline 51 & 0.05 & 0.07 & 0.02 & 0.02 & 0.12 & 0.14 & 0.03 & 0.04 \\
102 & 0.01 & 0.02 & 0.03 & 0.03 & 0.04 & 0.05 & 0.05 & 0.06 \\
203 & 0.01 & 0.02 & 0.02 & 0.02 & 0.02 & 0.03 & 0.03 & 0.04 \\
406 & 0.00 & 0.00 & 0.00 & 0.01 & 0.01 & 0.01 & 0.01 & 0.02 \\
610 & 0.00 & 0.01 & 0.02 & 0.02 & 0.01 & 0.01 & 0.03 & 0.04 \\
\hline
\end{tabular}

(b) $\zeta_{\text {set }}=2+i, M_{0}=0.0$

\begin{tabular}{|c|c|c|c|c|c|c|c|c|}
\hline & \multicolumn{3}{|c|}{ $\pm 0.25 \mathrm{~dB}$ and $\pm 0.5 \mathrm{deg}$} & \multicolumn{4}{c|}{ $\pm 0.5 \mathrm{~dB}$ and $\pm 1.0 \mathrm{deg}$} \\
\hline Liner Length, mm & $\theta_{\text {mean }}$ & $\theta_{\text {unc }}$ & $\chi_{\text {mean }}$ & $\chi_{\text {unc }}$ & $\theta_{\text {mean }}$ & $\theta_{\text {unc }}$ & $\chi_{\text {mean }}$ & $\chi_{\text {unc }}$ \\
\hline 51 & 0.09 & 0.10 & 0.13 & 0.16 & 0.19 & 0.18 & 0.21 & 0.38 \\
102 & 0.07 & 0.08 & 0.07 & 0.05 & 0.17 & 0.16 & 0.16 & 0.19 \\
203 & 0.03 & 0.03 & 0.05 & 0.08 & 0.05 & 0.07 & 0.12 & 0.17 \\
406 & 0.02 & 0.02 & 0.03 & 0.03 & 0.03 & 0.03 & 0.04 & 0.05 \\
610 & 0.02 & 0.03 & 0.03 & 0.04 & 0.02 & 0.03 & 0.05 & 0.07 \\
\hline
\end{tabular}

(c) $\zeta_{\text {set }}=1-i, M_{0}=0.3$

\begin{tabular}{|c|c|c|c|c|c|c|c|c|}
\hline & \multicolumn{3}{|c|}{ $\pm 0.25 \mathrm{~dB}$ and $\pm 0.5 \mathrm{deg}$} & \multicolumn{4}{c|}{ $\pm 0.5 \mathrm{~dB}$ and $\pm 1.0 \mathrm{deg}$} \\
\hline Liner Length, mm & $\theta_{\text {mean }}$ & $\theta_{\text {unc }}$ & $\chi_{\text {mean }}$ & $\chi_{\text {unc }}$ & $\theta_{\text {mean }}$ & $\theta_{\text {unc }}$ & $\chi_{\text {mean }}$ & $\chi_{\text {unc }}$ \\
\hline 51 & 0.14 & 0.13 & 0.08 & 0.10 & 0.24 & 0.26 & 0.15 & 0.19 \\
102 & 0.05 & 0.07 & 0.06 & 0.06 & 0.09 & 0.12 & 0.09 & 0.10 \\
203 & 0.01 & 0.02 & 0.03 & 0.04 & 0.02 & 0.04 & 0.06 & 0.08 \\
406 & 0.01 & 0.01 & 0.02 & 0.03 & 0.02 & 0.04 & 0.06 & 0.04 \\
610 & 0.00 & 0.01 & 0.02 & 0.02 & 0.01 & 0.01 & 0.04 & 0.05 \\
\hline
\end{tabular}

(d) $\zeta_{\text {set }}=2+i, M_{0}=0.3$

\begin{tabular}{|c|c|c|c|c|c|c|c|c|}
\hline & \multicolumn{3}{|c|}{ $\pm 0.25 \mathrm{~dB}$ and $\pm 0.5 \mathrm{deg}$} & \multicolumn{3}{c|}{ $\pm 0.5 \mathrm{~dB}$ and $\pm 1.0 \mathrm{deg}$} \\
\hline Liner Length, $\mathrm{mm}$ & $\theta_{\text {mean }}$ & $\theta_{\text {unc }}$ & $\chi_{\text {mean }}$ & $\chi_{\text {unc }}$ & $\theta_{\text {mean }}$ & $\theta_{\text {unc }}$ & $\chi_{\text {mean }}$ & $\chi_{\text {unc }}$ \\
\hline 51 & 0.25 & 0.19 & 0.25 & 0.33 & 0.25 & 0.41 & 0.49 & 0.59 \\
102 & 0.18 & 0.19 & 0.07 & 0.08 & 0.39 & 0.58 & 0.10 & 0.18 \\
203 & 0.04 & 0.05 & 0.05 & 0.09 & 0.08 & 0.11 & 0.17 & 0.21 \\
406 & 0.05 & 0.05 & 0.03 & 0.04 & 0.12 & 0.09 & 0.08 & 0.08 \\
610 & 0.03 & 0.03 & 0.04 & 0.03 & 0.07 & 0.05 & 0.10 & 0.05 \\
\hline
\end{tabular}


Table 8. Errors in impedances educed from synthesized acoustic pressures with random data scatter on the GFIT side wall, normalized by $\rho c(y=48 \mathrm{~mm}, \mathbf{3 0 0 0} \mathrm{Hz}$ source $)$

(a) $\zeta_{\text {set }}=1-i, M_{0}=0.0$

\begin{tabular}{|c|c|c|c|c|c|c|c|c|}
\hline & \multicolumn{3}{|c|}{ $\pm 0.25 \mathrm{~dB}$ and $\pm 0.5 \mathrm{deg}$} & \multicolumn{4}{c|}{ $\pm 0.5 \mathrm{~dB}$ and $\pm 1.0 \mathrm{deg}$} \\
\hline Liner Length, mm & $\theta_{\text {mean }}$ & $\theta_{\text {unc }}$ & $\chi_{\text {mean }}$ & $\chi_{\text {unc }}$ & $\theta_{\text {mean }}$ & $\theta_{\text {unc }}$ & $\chi_{\text {mean }}$ & $\chi_{\text {unc }}$ \\
\hline 51 & 0.02 & 0.03 & 0.01 & 0.01 & 0.04 & 0.04 & 0.02 & 0.02 \\
102 & 0.01 & 0.01 & 0.01 & 0.01 & 0.02 & 0.02 & 0.02 & 0.03 \\
203 & 0.00 & 0.00 & 0.00 & 0.00 & 0.01 & 0.01 & 0.01 & 0.01 \\
406 & 0.01 & 0.01 & 0.00 & 0.01 & 0.01 & 0.02 & 0.00 & 0.01 \\
610 & 0.01 & 0.01 & 0.01 & 0.01 & 0.02 & 0.04 & 0.01 & 0.02 \\
\hline
\end{tabular}

(b) $\zeta_{\text {set }}=2+i, M_{0}=0.0$

\begin{tabular}{|c|c|c|c|c|c|c|c|c|}
\hline & \multicolumn{3}{|c|}{ $\pm 0.25 \mathrm{~dB}$ and $\pm 0.5 \mathrm{deg}$} & \multicolumn{4}{c|}{ $\pm 0.5 \mathrm{~dB}$ and $\pm 1.0 \mathrm{deg}$} \\
\hline Liner Length, mm & $\theta_{\text {mean }}$ & $\theta_{\text {unc }}$ & $\chi_{\text {mean }}$ & $\chi_{\text {unc }}$ & $\theta_{\text {mean }}$ & $\theta_{\text {unc }}$ & $\chi_{\text {mean }}$ & $\chi_{\text {unc }}$ \\
\hline 51 & 0.03 & 0.05 & 0.02 & 0.03 & 0.05 & 0.10 & 0.04 & 0.09 \\
102 & 0.07 & 0.09 & 0.06 & 0.11 & 0.12 & 0.18 & 0.08 & 0.12 \\
203 & 0.02 & 0.03 & 0.07 & 0.07 & 0.05 & 0.06 & 0.08 & 0.11 \\
406 & 0.02 & 0.02 & 0.05 & 0.06 & 0.03 & 0.04 & 0.11 & 0.14 \\
610 & 0.01 & 0.02 & 0.03 & 0.04 & 0.03 & 0.04 & 0.09 & 0.09 \\
\hline
\end{tabular}

(c) $\zeta_{\text {set }}=1-i, M_{0}=0.3$

\begin{tabular}{|c|c|c|c|c|c|c|c|c|}
\hline & \multicolumn{3}{|c|}{ $\pm 0.25 \mathrm{~dB}$ and $\pm 0.5 \mathrm{deg}$} & \multicolumn{4}{c|}{ $\pm 0.5 \mathrm{~dB}$ and $\pm 1.0 \mathrm{deg}$} \\
\hline Liner Length, mm & $\theta_{\text {mean }}$ & $\theta_{\text {unc }}$ & $\chi_{\text {mean }}$ & $\chi_{\text {unc }}$ & $\theta_{\text {mean }}$ & $\theta_{\text {unc }}$ & $\chi_{\text {mean }}$ & $\chi_{\text {unc }}$ \\
\hline 51 & 0.01 & 0.02 & 0.02 & 0.03 & 0.05 & 0.07 & 0.03 & 0.03 \\
102 & 0.02 & 0.02 & 0.02 & 0.02 & 0.04 & 0.06 & 0.04 & 0.05 \\
203 & 0.01 & 0.01 & 0.01 & 0.02 & 0.01 & 0.01 & 0.03 & 0.03 \\
406 & 0.01 & 0.01 & 0.01 & 0.01 & 0.01 & 0.01 & 0.02 & 0.04 \\
610 & 0.01 & 0.01 & 0.01 & 0.01 & 0.01 & 0.01 & 0.03 & 0.04 \\
\hline
\end{tabular}

(d) $\zeta_{\text {set }}=2+i, M_{0}=0.3$

\begin{tabular}{|c|c|c|c|c|c|c|c|c|}
\hline & \multicolumn{3}{|c|}{ $\pm 0.25 \mathrm{~dB}$ and $\pm 0.5 \mathrm{deg}$} & \multicolumn{4}{c|}{ $\pm 0.5 \mathrm{~dB}$ and $\pm 1.0 \mathrm{deg}$} \\
\hline Liner Length, mm & $\theta_{\text {mean }}$ & $\theta_{\text {unc }}$ & $\chi_{\text {mean }}$ & $\chi_{\text {unc }}$ & $\theta_{\text {mean }}$ & $\theta_{\text {unc }}$ & $\chi_{\text {mean }}$ & $\chi_{\text {unc }}$ \\
\hline 51 & 0.03 & 0.06 & 0.03 & 0.04 & 0.06 & 0.07 & 0.04 & 0.08 \\
102 & 0.09 & 0.16 & 0.13 & 0.15 & 0.10 & 0.22 & 0.28 & 0.40 \\
203 & 0.04 & 0.05 & 0.06 & 0.06 & 0.08 & 0.09 & 0.09 & 0.13 \\
406 & 0.03 & 0.04 & 0.05 & 0.07 & 0.06 & 0.08 & 0.14 & 0.16 \\
610 & 0.03 & 0.02 & 0.03 & 0.05 & 0.06 & 0.07 & 0.14 & 0.12 \\
\hline
\end{tabular}


Table 9. Errors in impedances educed from synthesized acoustic pressures with random data scatter $(\{ \pm 0.00 \mathrm{~dB}, \pm 0.0 \mathrm{deg}\},\{ \pm 0.25 \mathrm{~dB}$, $\pm 0.5 \mathrm{deg}\}$ or $\{ \pm 0.50 \mathrm{~dB}, \pm 1.0 \mathrm{deg}\})$ on the CDTR wall adjacent to the liner, normalized by $\rho c$

(a) $M_{0}=0.0$

\begin{tabular}{|c|c|c|c|c|c|c|c|}
\hline \multicolumn{2}{|c|}{} & \multicolumn{2}{c|}{ $\pm 0.00 \mathrm{~dB}, \pm 0.0 \mathrm{deg}$} & \multicolumn{2}{c|}{ $\pm 0.25 \mathrm{~dB}, \pm 0.5 \mathrm{deg}$} & \multicolumn{2}{c|}{ $\pm 0.50 \mathrm{~dB}, \pm 1.0 \mathrm{deg}$} \\
\hline Frequency, Hz & $\zeta_{\text {set }}$ & $\theta_{\text {err }}$ & $\chi_{\text {err }}$ & $\theta_{\text {err }}$ & $\chi_{\text {err }}$ & $\theta_{\text {err }}$ & $\chi_{\text {err }}$ \\
\hline \multirow{3}{*}{1000} & $1-i$ & 0.00 & 0.00 & 0.01 & 0.01 & 0.01 & 0.01 \\
& $2+i$ & 0.00 & 0.00 & 0.02 & 0.08 & 0.03 & 0.08 \\
& $3-2 i$ & 0.00 & 0.00 & 0.13 & 0.07 & 0.23 & 0.18 \\
\hline \multirow{3}{*}{2000} & $1-i$ & 0.00 & 0.00 & 0.00 & 0.02 & 0.01 & 0.05 \\
& $2+i$ & 0.00 & 0.00 & 0.04 & 0.03 & 0.16 & 0.19 \\
& $3-2 i$ & 0.00 & 0.00 & 0.02 & 0.01 & 0.22 & 0.05 \\
\hline \multirow{3}{*}{3000} & $1-i$ & 0.00 & 0.00 & 0.01 & 0.05 & 0.02 & 0.09 \\
& $2+i$ & 0.00 & 0.00 & 0.07 & 0.19 & 0.19 & 0.21 \\
& $3-2 i$ & 0.00 & 0.00 & 0.02 & 0.03 & 0.17 & 0.04 \\
\hline
\end{tabular}

(a) $M_{0}=0.3$

\begin{tabular}{|c|c|c|c|c|c|c|c|}
\hline \multicolumn{2}{|c|}{} & \multicolumn{2}{c|}{ $\pm 0.00 \mathrm{~dB}, \pm 0.0 \mathrm{deg}$} & \multicolumn{2}{c|}{ $\pm 0.25 \mathrm{~dB}, \pm 0.5 \mathrm{deg}$} & \multicolumn{2}{|c|}{ $\pm 0.50 \mathrm{~dB}, \pm 1.0 \mathrm{deg}$} \\
\hline Frequency, Hz & $\zeta_{\text {set }}$ & $\theta_{\text {err }}$ & $\chi_{\text {err }}$ & $\theta_{\text {err }}$ & $\chi_{\text {err }}$ & $\theta_{\text {err }}$ & $\chi_{\text {err }}$ \\
\hline \multirow{3}{*}{1000} & $1-i$ & 0.00 & 0.00 & 0.01 & 0.00 & 0.03 & 0.01 \\
& $2+i$ & 0.00 & 0.00 & 0.02 & 0.05 & 0.03 & 0.28 \\
& $3-2 i$ & 0.00 & 0.00 & 0.12 & 0.18 & 0.30 & 0.52 \\
\hline \multirow{3}{*}{2000} & $1-i$ & 0.00 & 0.00 & 0.01 & 0.01 & 0.04 & 0.02 \\
& $2+i$ & 0.00 & 0.00 & 0.03 & 0.03 & 0.05 & 0.15 \\
& $3-2 i$ & 0.00 & 0.00 & 0.16 & 0.15 & 0.26 & 0.26 \\
\hline \multirow{3}{*}{3000} & $1-i$ & 0.00 & 0.00 & 0.00 & 0.01 & 0.02 & 0.00 \\
& $2+i$ & 0.00 & 0.00 & 0.06 & 0.16 & 0.22 & 0.25 \\
& $3-2 i$ & 0.00 & 0.00 & 0.10 & 0.01 & 0.06 & 0.09 \\
\hline
\end{tabular}

(a) $M_{0}=0.5$

\begin{tabular}{|c|c|c|c|c|c|c|c|}
\hline \multicolumn{2}{|c|}{} & \multicolumn{2}{c|}{ $\pm 0.00 \mathrm{~dB}, \pm 0.0 \mathrm{deg}$} & \multicolumn{2}{c|}{ $\pm 0.25 \mathrm{~dB}, \pm 0.5 \mathrm{deg}$} & \multicolumn{2}{c|}{ $\pm 0.50 \mathrm{~dB}, \pm 1.0 \mathrm{deg}$} \\
\hline Frequency, Hz & $\zeta_{\text {set }}$ & $\theta_{\text {err }}$ & $\chi_{\text {err }}$ & $\theta_{\text {err }}$ & $\chi_{\text {err }}$ & $\theta_{\text {err }}$ & $\chi_{\text {err }}$ \\
\hline \multirow{3}{*}{1000} & $1-i$ & 0.00 & 0.00 & 0.01 & 0.02 & 0.02 & 0.06 \\
& $2+i$ & 0.00 & 0.00 & 0.04 & 0.21 & 0.13 & 0.37 \\
& $3-2 i$ & 0.00 & 0.00 & 0.08 & 0.28 & 0.08 & 0.24 \\
\hline \multirow{3}{*}{2000} & $1-i$ & 0.00 & 0.00 & 0.01 & 0.01 & 0.05 & 0.03 \\
& $2+i$ & 0.00 & 0.00 & 0.04 & 0.20 & 0.11 & 0.11 \\
& $3-2 i$ & 0.00 & 0.00 & 0.03 & 0.00 & 0.26 & 0.26 \\
\hline \multirow{3}{*}{3000} & $1-i$ & 0.00 & 0.00 & 0.01 & 0.01 & 0.01 & 0.00 \\
& $2+i$ & 0.00 & 0.00 & 0.06 & 0.14 & 0.08 & 0.20 \\
& $3-2 i$ & 0.00 & 0.00 & 0.19 & 0.17 & 0.23 & 0.37 \\
\hline
\end{tabular}

